Article

\title{
Quantification and Evaluations of Catechin Hydrate Polymeric Nanoparticles Used in Brain Targeting for the Treatment of Epilepsy
}

\author{
Niyaz Ahmad ${ }^{1,2}$, , Rizwan Ahmad ${ }^{3}$,, Ridha Abdullah Alrasheed ${ }^{1}$, \\ Hassan Mohammed Ali Almatar ${ }^{1}$, Abdullah Sami Al-Ramadan ${ }^{1}$, \\ Mohd Amir ${ }^{3}$ and Md Sarafroz ${ }^{2}$ \\ 1 Department of Pharmaceutics, College of Clinical Pharmacy, Imam Abdulrahman Bin Faisal University, \\ Dammam 314441, Saudi Arabia; 2160003774@iau.edu.sa (R.A.A.); 2150004453@iau.edu.sa (H.M.A.A.); \\ 2160002963@iau.edu.sa (A.S.A.-R.) \\ 2 Department of Pharmaceutical Chemistry, College of Clinical Pharmacy, Imam Abdulrahman Bin Faisal \\ University, Dammam 314441, Saudi Arabia; mskausar@iau.edu.sa \\ 3 Department of Natural Products and Alternative Medicine, College of Clinical Pharmacy, Imam \\ Abdulrahman Bin Faisal University, Dammam 314441, Saudi Arabia; rareiyadh@iau.edu.sa (R.A.); \\ matahmad@iau.edu.sa (M.A.) \\ * Correspondence: nanhussain@iau.edu.sa or niyazpharma@gmail.com; \\ Tel.: +966-13-333-5541 or +966-531203626; Fax: +966-13-333-0290
}

Received: 7 February 2020; Accepted: 24 February 2020; Published: 27 February 2020

check for updates

\begin{abstract}
To formulate novel chitosan (CS)-coated-PLGA-nanoparticles (NPs) using a central composite design approach and use them in order to improve brain bioavailability for catechin hydrate $(\mathrm{CH})$ through direct nose-to-central nervous system (CNS) delivery for the evaluation of a comparative biodistribution study of $\mathrm{CH}$ by the newly developed ultra high performance liquid chromatography mass spectroscopy and mass spectroscopy (UHPLC-MS/MS) method in the treatment of epilepsy. For PLGA-NPs' preparation, a double emulsion-solvent evaporation method was used, where a four-factor, three-level central composite design was used to obtain the best nanoformulation. For the optimization, four independent variables were chosen, that is, PLGA, polyvinyl alcohol (PVA), sonication time, and temperature. The optimized PLGA-NPs were further coated with chitosan and assessed for drug release, nasal permeation study, as well as a comparative pharmacokinetic and pharmacodynamic study. Independent and dependent variables helped to optimize the best nanoformulation based on the composition of PLGA (50.0 mg), PVA (1.10\%), sonication time $(90.0 \mathrm{~s})$, and temperature $\left(25.0^{\circ} \mathrm{C}\right)$. The values of dependent variables were observed, such as polydispersity index (PDI), particle size, and zeta potential (ZP)—that is, $0.106 \pm 0.01$, $93.46 \pm 3.94 \mathrm{~nm}$, and $-12.63 \pm 0.08 \mathrm{mV}$, respectively. The ZPs of CS-coated PLGA-NPs were changed from negative to positive value with some alteration in the distribution of particle size. Excellent mucoadhesive-nature of CS-CH-PLGA-NPs as compared with CH-S and CH-PLGA-NPs was seen, with a retention time of $0.856 \mathrm{~min}$ and $\mathrm{m} / \mathrm{z}$ of $289.23 / 245.20$ for $\mathrm{CH}$, together with a retention time of $1.04 \mathrm{~min}$ and $\mathrm{m} / \mathrm{z}$ of 301.21/151.21 for Quercetin as an internal standard (IS). For a linear range (1-1000 $\left.\mathrm{ng} \mathrm{mL}^{-1}\right), \%$ accuracy $(93.07-99.41 \%)$ and inter- and intraday \% precision $(0.39-4.90 \%)$ were determined. The improved $\mathrm{C}_{\max }$ with area under curve (AUC) $)_{0-24}$ was found to be highly significant $(p<0.001)$ in Wistar rats' brain as compared with the i.n. and i.v. treated group based on the pharmacokinetics (PK) results. Furthermore, CS-CH-PLGA-NPs were found to be more significant $(p<0.001)$ for the treatment of seizure threshold rodent models, that is, increasing current electroshock and pentylenetetrazole-induced seizures. A significant role of CS-CH-PLGA-NPs was observed, that is, $p<0.001$, for the enhancement of brain bioavailability and the treatment of epilepsy.
\end{abstract}


Keywords: catechin hydrate; chitosan-coated-PLGA-nanoparticles; epilepsy; UHPLC-MS/MS; brain bioavailability and pharmacokinetic

\section{Introduction}

Nowadays, people (0.50-1.0\%) are suffering from serious neurological disorders, one example of which is epilepsy [1-3]. Numerous treatment processes are applied (surgery, drugs, and yoga) in order to control convulsions. Medicine is still one the most important parts of the treatment for seizures [4]. The researchers are focusing on glutamatergic neurotransmission and GABAergic (gamma-aminobutyric acid-ergic), which is the main path of the central nervous system for excitatory and inhibitory activity $[5,6]$. NHEs (sodium-hydrogen exchangers) are also involved in the regulation of seizures' activity for the neuronal cells $[7,8]$.

Medicine from natural sources is one the most important treatments, in addition to its use for medicinal, culinary, dietary, and curative purposes. Traditional and alternative source of medicines from plant sources are relied on for the development of good health and fewer side effects [9]. Camellia sinensis dried plant tea leaves are one of the most famous liquid refreshment drinks worldwide, followed similarly by water, which is the second most consumed [10]. Consumers use the leaves in the form of black tea, oolong tea, or green tea. Green tea in the market is attracting many people around the world, owing to various epidemiological and clinical studies data reporting positively on the prevention of many diseases. These established data have stated decreasing risk for cardiovascular diseases in terms of hypertension, myocardial infarction, and atherosclerosis; as well as for some degenerative diseases of neurons like Alzheimer's and Parkinson's diseases; followed by some specific cancers like gastric, cervical, and breast cancers, through the consumption of green tea by people [11-15]. All these effects came about thanks to the presence of the highest quantity of catechins (i.e., polyphenolic flavonoid compounds) in the green tea $[14,16]$. In the current time, there has been increased curiosity about the use of herbal drugs as another option for the development of formulations in therapeutic uses of various neurodegenerative diseases like epilepsy. All the mentioned effects of catechins are accredited to their antioxidant and anti-inflammatory action. Catechins are phytochemicals, richly present in black grapes, peaches, strawberries, and broad beans. Catechins occurring in various forms, such as epicatechin, catechins, catechin hydrate, epigallocatechin, epicatechin gallate, and epigallocatechin gallate, were reported to be used in the treatment of epilepsy $[17,18]$. Green tea and grape seed contained a sufficient amount of flavonoid that is, catechin hydrate (CH) [19]. It has also been proven previously that $\mathrm{CH}$ showed antioxidant and anti-inflammatory activities [20]. In the presence of these situations, the current study was designed to develop a novel nanoformulation and to evaluate the anticonvulsive effect of $\mathrm{CH}$ against epileptic induced rats.

Many researchers are focusing on nose-to-brain drug delivery systems as they have many advantages such as hepatic first pass metabolism, avoiding the blood brain barrier (BBB), and being a non-invasive route with easy administration of drugs [21-23]. Before designing the intranasal preparations, it is important to understand the problem of the short-stay time of the drug in the nasal cavity. It is highly recommended to develop formulations that contain maximum viscosity with mucoadhesive property; this will increase the nasal residence time. We can design the mucoadhesive formulation administered intranasally to enhance the absorption of the $\mathrm{CH}$ drug. We can design a certain dosage form that is helpful for increasing the nasal mucoadhesive time. Nowadays, in situ nasal gel formulations are an attractive tool used as biocompatible and biodegradable nanoparticles (NPs) for the sustained and controlled release of catechin hydrate $(\mathrm{CH})$ [24-28]. Polymeric NPs are attaining a great attention because of their ability to lengthen the therapeutic action, control the drug release rate, contain the maximum loading drug capacity (DL), and enhance the surface area. In this way, the drug will release rapidly when compared with various types of carriers and drug delivery systems for the specific sites targeted to the body. Polymeric NPs also provide additional advantages as compared with 
other nose-to-brain drug delivery systems because these NPs protect the drugs that are encapsulated, avoiding the direct involvement of biological degradation by chemical and extracellular transport via efflux of p-glyco proteins. Finally, it enhanced the bioavailability of drugs into the brain. NPs had a very small diameter, which is very useful for the transcellular transportation through olfactory neurons into the brain via various endocytic pathways of neuronal cells for the treatment of Parkinson's disease via olfactory membranes [26-28]. Therefore, these nanoparticles can be a better approach in the comparison of in situ nasal gel. Poly(lactic-co-glycolic acid) nanoparticles, that is, PLGA-NPs, having an optimum size, shape, and a specific surface, have been linked with the ligand, which is mostly utilized for intranasal brain targeting of the drugs [29]. PLGA-NPs are known to be biodegradable, biocompatible, and non-toxic, and have been used in biomedical applications for more than two decades. PLGA has been widely investigated for the formulation of NPs because of its biocompatibility, safety, ability to promote mucoadhesion, and enhanced drug stability via intranasal drug delivery as compared with other routes of drug administration [30,31]. PVA-NPs (polyvinyl alcohol NPs) are also used similarly because of the maximum permeability, better solubility, and increased compatibility of mixtures with excellent rheological properties on the various shapes and flexibility through many types of drug delivery [32]. Nowadays, chitosan exhibited a mucoadhesive nature, which attracted great attention in different fields like protein and metal adsorption $[27,28,33]$. Coating on the NPs' surface by chitosan (CS) has been shown to be useful in many applications like a sustained release of drug delivery, with mucoadhesive properties resulting in the enhancement of the drug absorption and prolonged release of drugs [28,34,35], decreasing the burst release of drugs because of the surface modification, and also enhancing the permeation and retention of NPs. This mechanism occurs because of the interest taken between the positively-charged CS and negatively-charged membrane $[28,34,35]$.

Likewise, the literature survey [33,36-43] reports different methods for sample analysis of fruit juices, green tea or tea extracts, and coffee or other plant extracts. Although, most of these research studies reported simultaneous development with other catechins at the same time, that is, no reports of plasma analysis are available for catechin individually. Only one method was reported in urine sample analysis for catechins by Lendoiro et al. [44]. In addition, the most important reason for the proposed study is a lack of an available method for brain tissue as well as plasma analysis of catechin hydrate alone. Likewise, no report is available for the quantification of $\mathrm{CH}$ up to picogram level in either the plasma or brain tissue. In this research study, we developed a new bioanalytical method of catechin hydrate and validated it successfully for the evaluation of the pharmacokinetic (PK) parameters of CS-coated-PLGA-NPs by ultra high performance liquid chromatography (UHPLC)-electrospray ionization (ESI)-triple-quadrupole-mass spectroscopy and mass spectroscopy (MS/MS). This developed bioanalytical method exhibited many applications in terms of higher efficiency, maximum sensitivity, minimum retention, and run time for the evaluation of PK parameters in plasma as well as brain in a shorter time. Additionally, the developed method is also recommended for the quantification of $\mathrm{CH}$ in the lungs for PK study.

The proposed research is a first time study designed to develop a new nanoformulation of chitosan (CS)-coated-PLGA-NPs for enhanced brain targeting of $\mathrm{CH}$. The main aim is to enhance $\mathrm{CH}$ bioavailability in the brain after the intranasal delivery of $\mathrm{CH}$ nanoformulations, to attain a high drug therapeutic level in the central nervous system (CNS), while avoiding the unwanted systemic exposure of the drug, along with the dose requirement for therapeutic advantage of the brain or systemic. CS-coated-PLGA-NPs exhibited the best effective solubility and permeability. CS-coated-CH-loaded-PLGA-NPs were developed and characterized for many physicochemical characteristics to evaluate their appropriateness for nose-to-brain drug delivery. A comparative research study was evaluated for the CH-S, CH-loaded-PLGA-NPs, and CS-coated-CH-loaded-PLGA-NPs in the brain, along with evaluation of PK parameters $\left(C_{\max }, t_{1 / 2} \text {, area under curve (AUC) }\right)_{0-t}, K_{e l}$, and so on) with their comparative bioavailability and study by the successfully developed and validated UHPLC-MS/MS method in the treatment of epilepsy (increasing current electroshock (ICES) and pentylenetetrazole (PTZ)) induced seizures for both rodent models. 


\section{Materials and Methods}

Catechin hydrate (purity 99.98\%) was purchased from AK Scientific, Inc. 30023 Ahern Avenue Union City, CA 94587, USA. Chitosan from Tokyo Chemical Industry Co., Ltd. 6-15-9 Toshima, Kita-ku, Tokyo 114-0003, Japan. Poly (vinyl alcohol, MW 25,000) and PLGA were purchased from Polysciences Inc, 400 Valley Road and dichloromethane (DCM) was purchased from Sigma Aldrich Corporation (St. Louis, MO, USA). HPLC-grade methanol, acetonitrile, ammonium formate, ammonium acetate, and formic acid were purchased from Sigma-Aldrich Corporation (St. Louis, MO, USA). Milli-Q-Water was used in the whole analysis. All the other chemicals used that were of analytical grade were obtained from different commercial sources.

\subsection{Preparation of Nanoparticles}

CH-PLGA-NPs were prepared and optimized through a previously used method, that is, double emulsion methods with slight modification $[28,45]$. In a summarized form, $\mathrm{CH}(10.00 \mathrm{mg})$ was dissolved in PVA solution $(400 \mu \mathrm{L}, 1.1 \% w / v, \mathrm{pH} 3.0$ adjusted) and PLGA (50.00 mg) was dissolved in dichloromethane (DCM; $8.0 \mathrm{~mL}$ ). Emulsification of polymeric solution was sonicated (over an ice bath) in drug solution for $1.5 \mathrm{~min}$ (duty cycles (40\%), $25 \mathrm{~W}$, Sonopuls, Bandelin, Germany). Previously prepared w/o primary emulsion was added drop by drop up to $8.0 \mathrm{~mL}$ of aqueous phase (external, $1.0 \% \mathrm{w} / \mathrm{v}$ PVA) under sonication (25\% amplitude, over an ice bath, $2.0 \mathrm{~min}$ ). Finally, the resultant dispersion preparation, that is, secondary emulsion $(\mathrm{w} / \mathrm{o} / \mathrm{w})$, was exposed under gentle magnetic stirring (400.00 rpm) for evaporation of the solvent at room temperature. Following evaporation of the solvent, the resultant nano-suspension was centrifuged (with 18,000 rpm for $20.0 \mathrm{~min}$ ), and the pellets were washed and lyophilized for $24.0 \mathrm{~h}\left(-50{ }^{\circ} \mathrm{C}, 0.015 \mathrm{mbar}\right.$ pressure $)$ to attain free flowing and simply dispersible lyophilized nanoparticles (Lab Conco., LPYH, Lock 6, USA freeze dryer).

\subsection{Optimization by Central Composite Design}

A four-factor, three-level central composite experimental design (CCD) [21] was employed for the optimization and evaluation of the correlation between the independent variables like PLGA $\left(X_{1}\right)$, PVA $\left(X_{2}\right)$, sonication time $\left(X_{3}\right)$, and temperature $\left(X_{4}\right)$, and the dependent (responses) variables including particle size $\left(\mathrm{Y}_{1}\right)$, polydispersity index $(\mathrm{PDI})\left(\mathrm{Y}_{2}\right)$, and zeta potential $\left(\mathrm{Y}_{3}\right)($ Table 1$)$. On the other side for the prediction of better response, CCD is better as compared with the Box-Benhnken design (BBD) [21], as BBD suggested formulation only, that is, independent variables' values (lower, middle, and higher). CCD, however, included two additional values, $(+\alpha)$ and $(-\alpha)$, in addition to the above-mentioned values in which the rotatability necessities of the design are enclosed [21]. As per the experimental runs, the preparation of a total of 30 formulations was constructed (Table 2). CCD was suggested to run a total of 30 randomized formulations on the basis of given values. On the basis of the total of 30 formulation runs, 16 were treated as the main suggested formulation with eight-axial points, followed by six as the centre points. In the end, the required constraints were applied. CCD software (Design-Expert 12, Stat-Ease, Inc., 1300 Godward St NE, Suite 6400, Minneapolis, MN 55413-2561, USA) based on the four-factor, three-level was suggested as a quadratic polynomial equation, given below:

$$
\begin{gathered}
Y=b_{0}+b_{1} X_{1}+b_{2} X_{2}+b_{3} X_{3}+b_{4} X_{4}+b_{12} X_{1} X_{2}+b_{14} X_{1} X_{4}+b_{23} X_{2} X_{3}+b_{24} X_{2} X_{4}+b_{34} X_{3} X_{4} \\
+b_{11} X_{1}^{2}+b_{22} X_{2}^{2}+b_{33} X_{3}^{2}+b_{44} X_{4}^{2}
\end{gathered}
$$

Table 1. Variables in "Design Expert" software for the preparation and optimization of catechin hydrate (CH) PLGA-nanoparticles (NPs). PVA, polyvinyl alcohol; PDI, polydispersity index.

\begin{tabular}{cccc}
\hline Factors & \multicolumn{3}{c}{ Levels } \\
\hline Independent Variables & Low $(\mathbf{- 1})$ & Medium (0) & High (+1) \\
\hline $\mathrm{X}_{1}=$ PLGA $(\mathrm{mg})$ & 50 & 175 & 300 \\
\hline $\mathrm{X}_{2}=$ PVA $(\%)$ & 0.5 & 2.0 & 4.0 \\
\hline
\end{tabular}


Table 1. Cont.

\begin{tabular}{cccc}
\hline Factors & \multicolumn{3}{c}{ Levels } \\
\hline Independent Variables & Low $(\mathbf{- 1})$ & Medium (0) & High (+1) \\
\hline $\mathrm{X}_{3}=$ Sonication Time $(\mathrm{s})$ & 30 & 150 & 300 \\
\hline $\mathrm{X}_{4}=$ Temperature $\left({ }^{\circ} \mathrm{C}\right)$ & 20 & 35 & 50 \\
\hline & Constraints & Importance \\
\hline & Independent Variables & \\
\hline $\mathrm{X}_{1}=$ PLGA $(\mathrm{mg})$ & Minimize & ++++++ \\
\hline $\mathrm{X}_{2}=$ PVA $(\%)$ & Minimize & ++++ \\
\hline $\mathrm{X}_{3}=$ Sonication Time $(\mathrm{s})$ & Minimize within the range & +++++++ \\
\hline $\mathrm{X}_{4}=$ Temperature $\left({ }^{\circ} \mathrm{C}\right)$ & In range & ------ \\
\hline & Dependent variables & \\
\hline $\mathrm{Y}_{1}=$ Particle size $(\mathrm{nm})$ & Minimize & +++++ \\
\hline $\mathrm{Y}_{2}=$ PDI & Minimize & ++++ \\
\hline $\mathrm{Y}_{3}=$ Zeta Potential $(\mathrm{mV})$ & Maximize & +++++ \\
\hline
\end{tabular}

Table 2. Formulations recommended by "Design Expert" software, independent variables, and their responses.

\begin{tabular}{|c|c|c|c|c|c|c|c|c|c|c|}
\hline \multirow{3}{*}{ Formulation Code } & \multirow{2}{*}{\multicolumn{4}{|c|}{$\begin{array}{c}\text { Independent Variables } \\
\text { Coded Factors } \\
\end{array}$}} & \multicolumn{6}{|c|}{ Dependent Variables } \\
\hline & & & & & \multicolumn{3}{|c|}{ Observed Responses } & \multicolumn{3}{|c|}{ Predicted Responses } \\
\hline & $X_{1}$ & $X_{2}$ & $X_{3}$ & $X_{4}$ & $\mathrm{Y}_{1}$ & $\mathrm{Y}_{2}$ & $Y_{3}$ & $\mathrm{Y}_{1}$ & $Y_{2}$ & $\mathrm{Y}_{3}$ \\
\hline PLGA1 & 50 & 0.5 & 30 & 20 & $36.00 \pm 2.01$ & $0.063 \pm 0.001$ & $-8.12 \pm 0.09$ & 38.56 & 0.051 & -38.53 \\
\hline PLGA2 & 300 & 0.5 & 30 & 20 & $341.08 \pm 11.01$ & $0.394 \pm 0.021$ & $-31.09 \pm 3.11$ & 340.16 & 0.395 & -31.13 \\
\hline PLGA3 & 50 & 4 & 30 & 20 & $266.89 \pm 7.35$ & $0.412 \pm 0.032$ & $-28.43 \pm 2.91$ & 266.60 & 0.413 & -28.36 \\
\hline PLGA4 & 300 & 4 & 30 & 20 & $451.43 \pm 18.54$ & $0.506 \pm 0.053$ & $-30.18 \pm 2.98$ & 453.41 & 0.505 & -31.08 \\
\hline PLGA5 & 50 & 0.5 & 300 & 20 & $170.52 \pm 4.27$ & $0.316 \pm 0.026$ & $-21.42 \pm 2.18$ & 171.64 & 0.318 & -21.50 \\
\hline PLGA6 & 300 & 0.5 & 300 & 20 & $396.47 \pm 13.54$ & $0.539 \pm 0.041$ & $-27.35 \pm 3.11$ & 397.10 & 0.540 & -27.13 \\
\hline PLGA7 & 50 & 4 & 300 & 20 & $241.67 \pm 7.84$ & $0.394 \pm 0.019$ & $-24.51 \pm 2.01$ & 241.07 & 0.395 & -24.87 \\
\hline PLGA8 & 300 & 4 & 300 & 20 & $496.37 \pm 19.64$ & $0.643 \pm 0.073$ & $-32.64 \pm 4.06$ & 497.64 & 0.644 & -32.62 \\
\hline PLGA9 & 50 & 1.1 & 90 & 25 & $93.46 \pm 3.94$ & $0.106 \pm 0.010$ & $-12.63 \pm 0.08$ & 94.14 & 0.108 & -12.61 \\
\hline PLGA10 & 300 & 0.5 & 30 & 50 & $371.46 \pm 12.64$ & $0.367 \pm 0.013$ & $-28.45 \pm 2.93$ & 370.75 & 0.368 & -28.43 \\
\hline PLGA11 & 50 & 4 & 30 & 50 & $291.58 \pm 8.64$ & $0.423 \pm 0.034$ & $-26.47 \pm 2.16$ & 289.29 & 0.424 & -26.45 \\
\hline PLGA12 & 300 & 4 & 30 & 50 & $446.48 \pm 19.31$ & $0.583 \pm 0.050$ & $-27.94 \pm 3.18$ & 445.10 & 0.584 & -27.91 \\
\hline PLGA13 & 50 & 0.5 & 300 & 50 & $121.34 \pm 3.59$ & $0.416 \pm 0.031$ & $-19.34 \pm 1.97$ & 120.98 & 0.417 & -19.31 \\
\hline PLGA14 & 300 & 0.5 & 300 & 50 & $366.49 \pm 12.26$ & $0.411 \pm 0.016$ & $-16.49 \pm 1.64$ & 368.09 & 0.412 & -16.46 \\
\hline PLGA15 & 50 & 4 & 300 & 50 & $221.64 \pm 6.78$ & $0.389 \pm 0.026$ & $-18.64 \pm 1.77$ & 222.34 & 0.388 & -18.61 \\
\hline \multirow[t]{2}{*}{ PLGA16 } & 300 & 4 & 300 & 50 & $549.67 \pm 21.97$ & $0.678 \pm 0.040$ & $-32.14 \pm 3.09$ & 548.15 & 0.676 & -32.13 \\
\hline & & & & & Axial Points & & & & & \\
\hline PLGA17 & 75 & 2.25 & 165 & 35 & $348.64 \pm 11.19$ & $0.496 \pm 0.033$ & $-21.45 \pm 2.05$ & 349.06 & 0.495 & -21.44 \\
\hline PLGA18 & 425 & 2.25 & 165 & 35 & $414.68 \pm 18.67$ & $0.506 \pm 0.042$ & $-23.64 \pm 2.37$ & 415.64 & 0.507 & -23.61 \\
\hline PLGA19 & 175 & 1.25 & 165 & 35 & $313.54 \pm 9.91$ & $0.436 \pm 0.029$ & $-14.56 \pm 2.69$ & 312.47 & 0.438 & -14.50 \\
\hline PLGA20 & 175 & 5.75 & 165 & 35 & $496.89 \pm 20.54$ & $0.694 \pm 0.043$ & $-33.54 \pm 4.68$ & 495.05 & 0.696 & -33.55 \\
\hline PLGA21 & 175 & 2.25 & 105 & 35 & $233.65 \pm 6.92$ & $0.405 \pm 0.031$ & $-16.64 \pm 1.94$ & 234.24 & 0.404 & -16.65 \\
\hline PLGA22 & 175 & 2.25 & 435 & 35 & $311.69 \pm 9.68$ & $0.589 \pm 0.053$ & $-21.64 \pm 2.11$ & 313.74 & 0.590 & -21.62 \\
\hline PLGA23 & 175 & 2.25 & 165 & 5 & $468.64 \pm 19.16$ & $0.711 \pm 0.064$ & $-31.64 \pm 3.64$ & 469.56 & 0.712 & -31.61 \\
\hline PLGA24 & 175 & 2.25 & 165 & 65 & $331.54 \pm 11.09$ & $0.642 \pm 0.039$ & $-19.34 \pm 1.91$ & 330.05 & 0.641 & -19.32 \\
\hline
\end{tabular}


Table 2. Cont.

\begin{tabular}{|c|c|c|c|c|c|c|c|c|c|c|}
\hline \multirow{3}{*}{ Formulation Code } & \multirow{2}{*}{\multicolumn{4}{|c|}{$\begin{array}{c}\text { Independent Variables } \\
\text { Coded Factors }\end{array}$}} & \multicolumn{6}{|c|}{ Dependent Variables } \\
\hline & & & & & \multicolumn{3}{|c|}{ Observed Responses } & \multicolumn{3}{|c|}{ Predicted Responses } \\
\hline & $X_{1}$ & $X_{2}$ & $X_{3}$ & $X_{4}$ & $Y_{1}$ & $\mathrm{Y}_{2}$ & $Y_{3}$ & $\mathrm{Y}_{1}$ & $\mathrm{Y}_{2}$ & $\mathrm{Y}_{3}$ \\
\hline \multicolumn{11}{|c|}{ Centre Points } \\
\hline PLGA25 & 175 & 2.25 & 165 & 35 & $289.64 \pm 12.08$ & $0.569 \pm 0.059$ & $-20.56 \pm 2.09$ & 291.01 & 0.570 & -21.06 \\
\hline PLGA26 & 175 & 2.25 & 165 & 35 & $289.64 \pm 12.08$ & $0.569 \pm 0.059$ & $-20.56 \pm 2.09$ & 291.01 & 0.570 & -21.06 \\
\hline PLGA27 & 175 & 2.25 & 165 & 35 & $289.64 \pm 12.08$ & $0.569 \pm 0.059$ & $-20.56 \pm 2.09$ & 291.01 & 0.570 & -21.06 \\
\hline PLGA28 & 175 & 2.25 & 165 & 35 & $289.64 \pm 12.08$ & $0.569 \pm 0.059$ & $-20.56 \pm 2.09$ & 291.01 & 0.570 & -21.06 \\
\hline PLGA29 & 175 & 2.25 & 165 & 35 & $289.64 \pm 12.08$ & $0.569 \pm 0.059$ & $-20.56 \pm 2.09$ & 291.01 & 0.570 & -21.06 \\
\hline PLGA30 & 175 & 2.25 & 165 & 35 & $289.64 \pm 12.08$ & $0.569 \pm 0.059$ & $-20.56 \pm 2.09$ & 291.01 & 0.570 & -21.06 \\
\hline
\end{tabular}

\subsection{Nanoparticles' Characterizations}

\subsubsection{Particle Size, PDI (Polydispersity Index), and Zeta Potential}

Measurement of the particle size is the most important parameter. The lower the particle size, the greater the surface area for the absorption of drug [28,45]. The particle size, polydispersity index, and Zeta potential of optimized NPs were measured by dynamic light scattering (Malvern-Zetasizer, Nano-Zetasizer, Worcestershire, UK. The nano-formulations were diluted prior to size analysis. The temperature maintained for the particle size analysis, that is, $25^{\circ} \mathrm{C}$, and the scattering angle were also fixed $\left(90^{\circ}\right)[28,45]$. The diluted sample of the nano-formulations was used to analyse the size and surface charge, where each measurement was made in triplicate.

\subsubsection{Chitosan Coating on Optimized CH-PLGA-NPs}

For chitosan-coated-PLGA-NPs' preparation, a specific-volume of CH-PLGA-NPs was kept at room temperature for $2.0 \mathrm{~h}$ with an equivalent volume of $\mathrm{CH}$, that is, $2.0 \mathrm{mg} / \mathrm{mL}$ or $4.0 \mathrm{mg} / \mathrm{mL}$ chitosan in the $0.50 \%$ of acetic acid [28,45]. The CS $(2 \%)$-coated-PLGA-NPs and CS $(4 \%)$-coated-PLGA-NPs were produced, centrifuged, washed twice, and then redispersed in the same volume of distilled water. Finally, they were dried with the help of a lyophilizer at $-60.0^{\circ} \mathrm{C}$ for four days (Labconco, TriadTM, USA) for the stability of NPs. These formulations were prepared in triplicate.

\subsubsection{Scanning Electron Microscopy (SEM)}

The shape of particles was determined by scanning electron microscopy (SEM) (FEI, INSPECT S50, Czech Republic). The proposed method was adopted from Ahmad et al. [28,34].

\subsubsection{Transmission Electron Microscopy (TEM)}

The globule size of optimized nanoparticles was examined by transmission electron microscopy (TEM) (FEI, MORGAGNE.68, Czech Republic). The proposed method was adopted by Ahmad et al. [28,34].

2.3.5. Loading Capacity (\%LC), Entrapment Efficiency (\%EE), and \%Process Yield of Prepared and Optimized Nanoparticles

The EE (entrapment efficiency) and LC (loading capacity) of NPs was determined by ultracentrifugation (at 15,000 rpm; $30 \mathrm{~min}$ at $4{ }^{\circ} \mathrm{C}$ ). In-house reported in this manuscript, the UHPLC-MS/MS method was used to evaluate and validate the free quantity of $\mathrm{CH}$ in supernatant $[28,34]$. After triplicate measurements, the following equation was used to calculate LC and EE for developed and optimized nanoparticles [28,34]:

$$
E E(\%)=\frac{\text { Total Quantity of } \mathrm{CH}-\text { Free Quantity of } \mathrm{CH}}{\text { Total Quantity of } \mathrm{CH}}
$$




$$
L C(\%)=\frac{\text { Total Quantity of } \mathrm{CH}-\text { Free Quantity of } \mathrm{CH}}{\text { Weight of Nanoparticles }}
$$

Process yield (\%) was calculated using the proposed formula:

$$
\text { Process Yield }(\%)=\frac{W_{1}(\text { Weight of Dried Nanoparticles })}{W_{2}(\text { Total Dried Weight of Starting Materials })}
$$

\subsubsection{DSC (Differential Scanning Calorimetry) Study}

DSC 214 Polyma (NETZSCH—Wittelsbacherstraße 42, 95100 Selb, Germany) was used to determine the DSC of pure catechin (CH); polymer (PLGA); poly vinyl alcohol (PVA); a physical mixture of $\mathrm{CH}, \mathrm{PVA}$, and PLGA; freeze-dried-CH-loaded-optimized polymer (PLGA)-NPs; pure chitosan; and CS-coated-CH-loaded-optimized polymer (PLGA)-NPs. The sample (10 mg) was kept inside a standard aluminium pan, crimped, and heated $\left(20.0^{\circ} \mathrm{C}\right.$ to $\left.400.0^{\circ} \mathrm{C}\right)$ at a rate of $10.0^{\circ} \mathrm{K} / \mathrm{min}$, followed by a continuous supply of nitrogen $[21,28,34]$.

\subsubsection{Fourier Transform Infrared Spectroscopy (FTIR)-Based Attenuated Total Reflection (ATR)}

Functional groups and chemical structures with their composition of the compounds were evaluated by FTIR-based ATR (NICOLET iS50 FT-IR; Thermo Fisher Scientific, 5225 Verona Road, Madison, WI 53711, USA). IR spectra of pure catechin hydrate (CH), PVA, PLGA-NPs, $\mathrm{CH}$-loaded-PLGA-NPs, chitosan, and chitosan-coated-CH-loaded-PLGA-NPs were examined through an attenuated total reflectance (ATR, wavenumber $4000-400 \mathrm{~cm}^{-1}$ ). All the samples were analysed in their original forms without any kind of preparation [46].

\subsection{In Vitro Drug Release}

In vitro release of $\mathrm{CH}$ from catechin hydrate suspension (CH-S) and optimized (opt)-both-NPs was carried out from the dialysis membrane (treated before) (pore size: $2.40 \mathrm{~nm}$, molecular weight cut-off $\sim 12-14 \mathrm{kD}$ ) [28,45]. First, the release medium was prepared (phosphate buffer/ethanol of 7:3; $\mathrm{pH} 7.4=100 \mathrm{~mL}$ ). The temperature was maintained at $37 \pm 1{ }^{\circ} \mathrm{C}$ with the help of a stirrer up to $6 \mathrm{~h}$ at $100 \mathrm{rpm}$. Finally, the dialysis bag was properly checked for any leak and $\mathrm{CH}-\mathrm{NPs}$ (containing $0.50 \mathrm{mg}$ $\mathrm{CH})$ were placed inside. For the $\mathrm{CH}$ release study from the NPs selected, the selected time points were predetermined (i.e., 30, 60, 120, 240, 360, 480, 720, and $1440 \mathrm{~min}$ ). At every time point, we withdrew the test samples $(1.0 \mathrm{~mL})$. All samples were withdrawn and filtered by syringe filter $(0.2 \mu \mathrm{m})$, after which the $\mathrm{CH}$ quantity was analysed through the in-house developed and validated UHPLC-MS/MS method reported in this manuscript $[28,46]$.

\subsection{Nasal Mucosa Based Ex Vivo Permeation Studies}

Nasal tissues were taken out freshly and carefully from the goat's nasal cavities provided by the local slaughterhouse. Tissue cells (a fix area) were decided to be used to permeate the drug $\left(0.785 \mathrm{~cm}^{2}\right.$; Logan Instrument Corporation, Piscataway, NJ, USA). Phosphate buffer saline $(20 \mathrm{~mL}$ PBS; pH 7.4, at $37^{\circ} \mathrm{C}$ ) was added to the receptor chamber, while pure $\mathrm{CH}$ suspension, freeze-dried CH-loaded-optimized-PLGA-NPs, and freeze-dried CS-coated-CH-loaded-optimized-PLGA-NPs ( $\sim 10.0 \mathrm{mg}$ of $\mathrm{CH}$ ) were kept in the donor chamber (21.5 to $2 \mathrm{~mL})$ after the preincubation time (20 min in each case). Then, $0.500 \mathrm{~mL}$ samples (on predetermined time intervals) were withdrawn from the receptor chamber. The samples were filtered via a membrane filter for the analysis. The quantity of permeated $\mathrm{CH}$ was analysed through the in-house developed and validated UHPLC-MS/MS method reported in this manuscript [46]. 


\subsection{In Vivo Study}

Ethical Committee of Imam Abdulrahman Bin Faisal University (IAU) gave us ethical approval to perform the pharmacokinetics and pharmacodynamics studies (Approval Number: IRB-UGS-2019-05-312, date of approval: 7 November 2019). Albino rats (weight; 180-200 g) were grouped (5 to 10 in each cage) and maintained in natural light followed by a dark cycle with freely reachable food and water (temperature: 20.0 to $30.0{ }^{\circ} \mathrm{C}$, humidity: $50.0 \%$ to $55.0 \%$ ). Albino rats of 180 to $200 \mathrm{~g}$ in weight were taken and kept in the cages on the basis of their predetermined groups. We also maintained a natural light/dark cycle with freely reachable food and water (temperature: 20-30 ${ }^{\circ} \mathrm{C}$, humidity: 50-55\%). All of the rats were kept under all of the prescribed conditions of the laboratory. At the wake up time, that is, the light cycle, the research work was started with freely moving rats.

\subsection{Development and Validation of Bioanalytical Method}

At the time of the development of bioanalytical methods and their validation for catechin hydrate of plasma, lungs, and brain homogenate, the U.S. FDA 2001 guidelines were followed. Eight levels of non-zero concentration for the calibration curve (CC) were selected to plot linearity and calculate the peak area ratio; $1 / x^{2}$ weighed linear smallest square regression was used. The noise ratio (10:1) was used as a signal to determine the LLOQ (lower limit of quantification) of the CC (LLOQ), in which HQC (higher quality control), medium QC (MQC), and lower QC (LQC) were used to examine the efficiency of $\mathrm{CH}$ extraction. For the evaluation of plasma, lungs, and brain homogenate samples, we took six pre-spiked extracted samples (mean area response) versus post-extraction spiked $\mathrm{CH}$-free in the matrix. Similarly, the recovery of internal standard (IS) samples was also estimated. For the estimation of inter- and intra-day precision and accuracy, we analysed six replicates of LLOQ of quality control (LLOQQC), LQC, MQC, and HQC with a CC of plasma, lungs, and brain homogenate samples.

\subsection{UHPLC-MS/MS Conditions}

UHPLC-MS/MS, that is, Pinnacle DB C18 $(1.9 \mu \mathrm{m} ; 50 \times 30.0 \mathrm{~mm})$, using a binary solvent manager autosampler with a very sensitive and high resolution tunable mass detector (LCMS-8050, ESI, Triple Quadrupole, Kyoto, Japan), was employed. Chromatographic conditions were used as Pinnacle DB C18 $(1.9 \mu \mathrm{m} ; 50 \times 30.0 \mathrm{~mm})$, mobile phase (methanol/formic acid (0.01\%): 54:36), flow rate $(0.250 \mathrm{~mL}$ $\mathrm{min}^{-1}$ ), and $5.0 \mu \mathrm{L}$ injection volume with a total run time of $2.0 \mathrm{~min}$. For mass determination, a very sensitive and high resolution tunable mass detector (LCMS-8050, ESI, Triple Quadrupole, Kyoto, Japan) was applied through operating conditions as follows: argon as collision gas, $1.0 \mathrm{~min}$ scan time, inter-scan delay $(0.02 \mathrm{~s}$ with $0.1 \mu$ scan step: $30,000 \mu / \mathrm{s})$, where for quantification of $\mathrm{CH}$ and IS, the parameters were used as collision energy (17.0 eV CE; for $\mathrm{CH}$ and $21.0 \mathrm{eV}$ for quercetin) with -ve ion mode. The parameters for bioanalysis illustrated a transition at $\mathrm{m} / \mathrm{z} 289.20 / 245.20$ and 301.21/151.21 for $\mathrm{CH}$ and quercetin (IS), respectively (Figures 1 and 2). For the accurate mass calculation with the concentration of analyte, as well as evaluation of precursor and fragment ions, we used the Lab Solution Software Version 5.93 (Kyoto, Japan).

\subsection{Preparation of QC and CC Samples}

First, we prepared standard $\mathrm{CH}$ stock solution in the methanol, that is, $1 \mathrm{mg} \mathrm{mL}^{-1}$ and then other dilutions for eight different concentrations of CC with the help of $2 \%$ analyte (aqueous) in blank matrix (plasma, lungs, and brain homogenate) of the rats, that is, analyte (20.0 $\mathrm{mL}$ of aqueous) + $980.0 \mathrm{~mL}$ matrix (blank). We prepared the CC samples at a range $(1.00-1000.00 \mathrm{ng} / \mathrm{mL})$ for $\mathrm{CH}$ with eight different time points $(1.0,2.0,22.0,210.0,420.0,640.0,850.0$, and $1000.0 \mathrm{ng} / \mathrm{mL})$ in the different matrixes. Similarly, we also prepared the QC samples HQC (800.00), MQC (410.00), LQC (2.90), and LLOQC (1.01) with IS (50.00 $\mathrm{ng} \mathrm{ml}^{-1}$ ) in a mixture of water/methanol (1:1). All the spiking dilutions prepared freshly and stored at a temperature of $2.0-8.0^{\circ} \mathrm{C}$. 

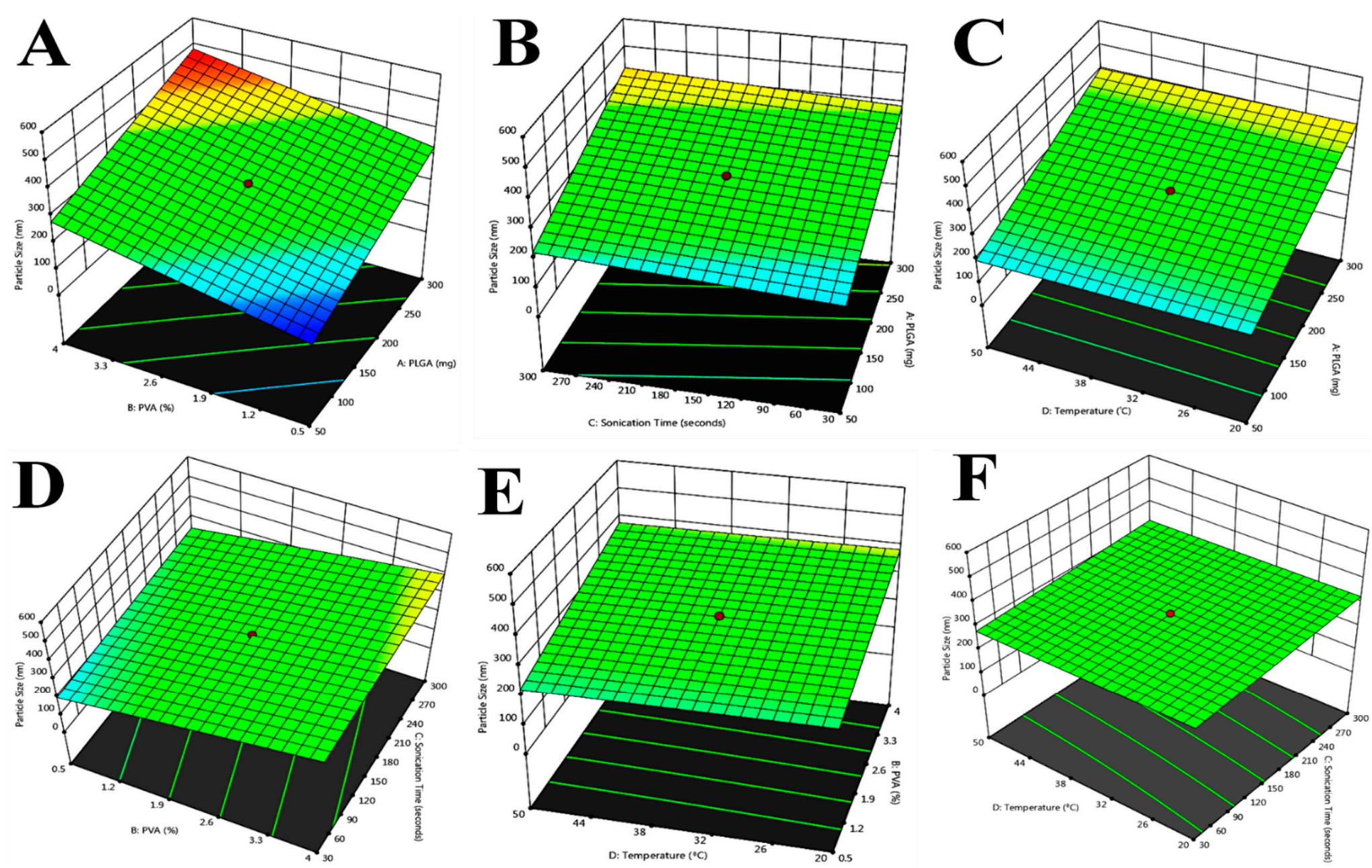

Figure 1. Response surface plot showing the effect of independent variables on particle size. PVA, PLGA. (A). Particle size, PLGA, sonication time; (B). Particle size, PLGA, temperature; (C). Particle size, PVA $(\%)$, sonication time; (D). Particle size, PVA $(\%)$, temperature $\left({ }^{\circ} \mathrm{C}\right) ;(\mathbf{E})$. Particle size, PVA $(\%)$, temperature $\left({ }^{\circ} \mathrm{C}\right) ;(\mathbf{F})$. Particle size, sonication time, temperature $\left({ }^{\circ} \mathrm{C}\right)$. 

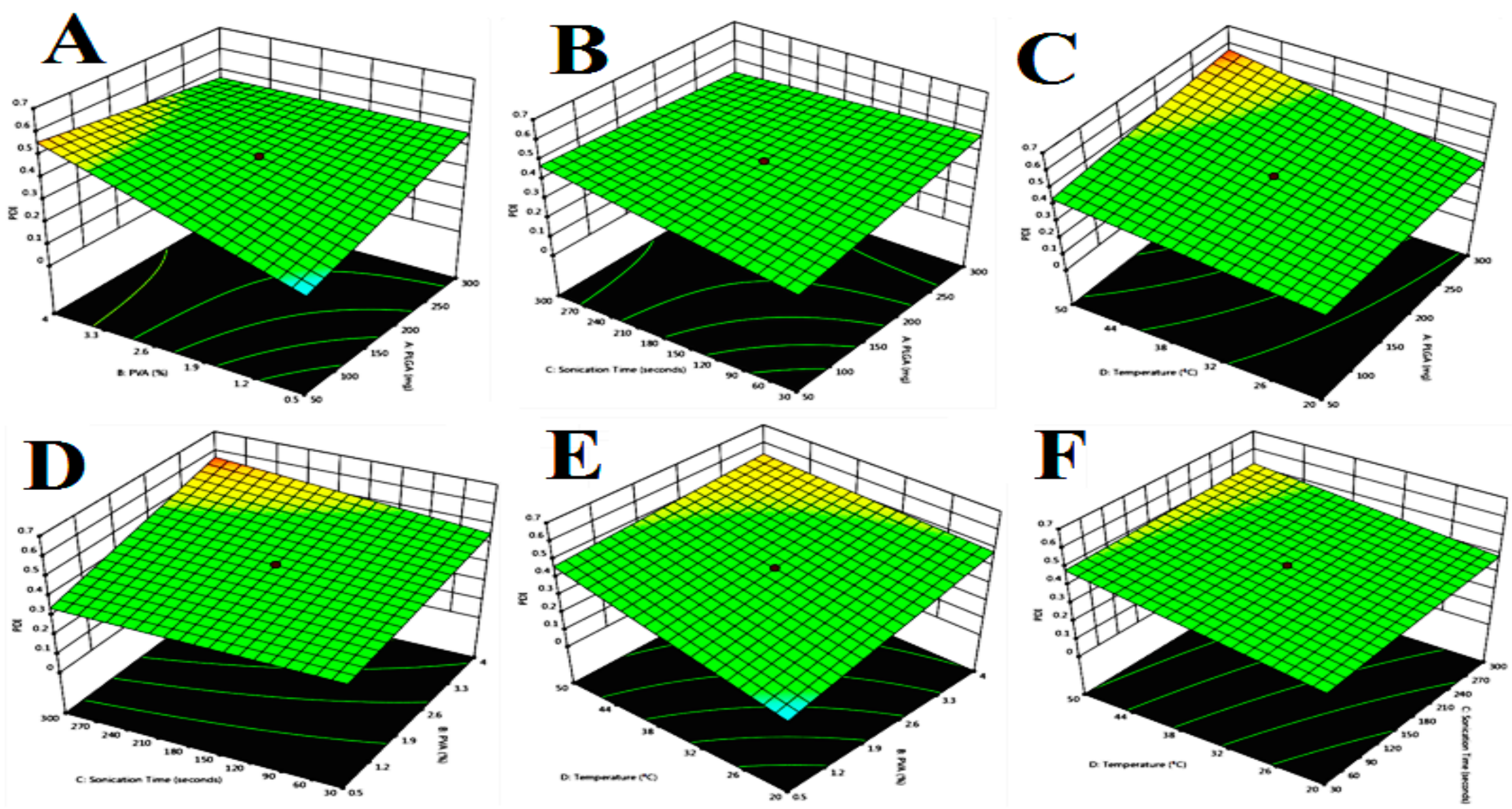

Figure 2. Response surface plot showing the effect of independent variables on polydispersity index (PDI), PLGA, PVA (\%); (A). PDI, PLGA, sonication time; (B). PDI, PLGA, temperature; (C). PDI, PVA (\%), sonication time; (D). PDI, PVA (\%), temperature; (E). PDI, temperature, sonication time; (F). PDI, temperature, sonication time. 


\subsection{Extraction of Different Matrix Samples}

Fresh known samples (CC and QC) with unknown samples of lungs, brain homogenate, or plasma were prepared and collected for analysis. For the extraction of all the matrix samples, $750.0 \mu \mathrm{L}$ of each aliquot was taken in a fresh-cleaned glass tube and then added to $50.0 \mathrm{ng} \mathrm{mL}^{-1}$ of $100.0 \mu \mathrm{L}$ of IS. Then, $250 \mu \mathrm{L} 5.0 \%$ formic acid was added by $300 \mathrm{rpm}$ vortexing up to $6.0 \mathrm{~min}$ for the breaking of matrixes' protein. All these samples were centrifuged at $4000 \mathrm{rpm}$ for $10.0 \mathrm{~min}$ at $4.0^{\circ} \mathrm{C}$, and then transferred to $4.0 \mathrm{~mL}$ supernatant sample in a clean glass tube. Transferred samples were evaporated at $37.0^{\circ} \mathrm{C}$ in a water bath for the purpose of drying the samples under nitrogen stream. Finally, the residues were reconstituted from a $650.0 \mu \mathrm{L}$ mobile phase with the help of $300 \mathrm{rpm}$ vortexed for $5.0 \mathrm{~min}$. All the reconstituted samples were transferred to UHPLC vials for bioanalysis.

\subsection{Pharmacokinetic (PK) Study}

We selected six groups for PK study, Group 1: $\mathrm{CH}-\mathrm{S}$ (i.n.), Group 2: $\mathrm{CH}-\mathrm{S}$ (i.v.), Group 3: CH-PLGA-NPs (i.n.), Group 4: CH-PLGA-NPs (i.v.), Group 5: CS-coated-CH-PLGA-NPs (i.n.), and Group 6: CS-coated-CH-PLGA-NPs (i.v.), with a dose $\mathrm{CH}=10.0 \mathrm{mg} / \mathrm{kg}$ body weight. Four rats were taken for each sampling time of all six groups. The blood was collected and then the rats were sacrificed with immediate removal of the brains and lungs for each sampling time of all six groups, followed by preparation of the lungs or brain homogenate. For the extraction of different matrixes, we applied the same procedure mentioned above in the extraction of different sections of matrix samples for the bioanalysis and PK analysis. All the test samples were collected at different sampling time point intervals, such as $0.00 \mathrm{~h}$ (pre-dose without treated), followed by treated samples $(0.50,1.00,2.00$, $4.00,8.00,12.00$, and $24.00 \mathrm{~h}$ ). These collected samples were processed as mentioned above and then analyzed by the in-house bioanalytical method for quantification of half-life, $\mathrm{K}_{\mathrm{e}}, \mathrm{C}_{\max }$, and $\mathrm{AUC}_{0-\mathrm{t}}$. A total of 32 rats were for each group $(4 \times 8=32)$ and the total number of rats for the whole PK study was 192 (32 rats for every group $\times 6$ groups $=192$ ), which were also given a dose as mentioned above. The blood of four rats from each group was collected, and then the rats were scarified, followed by immediate removal of the brains and lungs. The homogenate was prepared for all samples separately and analyzed by the in-house bioanalytical method [46].

\subsection{Pharmacodynamic Activity}

\subsubsection{Seizures Developed by PTZ}

The dose for each rat based their body weight $(70.0 \mathrm{mg} / \mathrm{kg}$ PTZ) was given intra-peritoneal, and they were observed for half an hour for myoclonic jerks as well as for clonic generalized seizures, which were noted [21,47]. For the development of PTZ seizure, we divided the rats into four groups as follows: Group 1 (normal saline treated/control group), Group 2 (catechin hydrate simple suspension treated), Group 3 (CH-PLGA-NPs treated), and Group 4 (CS-coated-CH-loaded-PLGA-NPs treated).

\subsubsection{Seizures Developed by ICES}

For the ICES seizure development, we used and modified the Kitano et al. and Ahmad et al. method $[21,48]$ to see the effects of $\mathrm{CH}$. In brief, the electroshock $(2.0 \mathrm{~mA}$ current) was initially as a single train of pulse $(20.0 \mathrm{~Hz}$ square wave for $0.20 \mathrm{~s})$ to each rat by the ears electrodes, in which the electroshock intensity was enhanced linearly as $2.0 \mathrm{~mA} / 2.0 \mathrm{~s}$. The tonic hind limb extension (HLE) point came and the intensity of the current, that is, the seizure threshold current (STC), was noted. Additionally, tonic HLE was applied up to a current of $50.0 \mathrm{~mA}$, and finally, the resulting electroshock was found. Finally, the cut-off current was noted and employed for analysis. The total of four groups of rats $(6 \times 4=24)$ were taken as Group 1 (normal saline treated), Group 2 (catechin hydrate simple suspension treated), Group 3 (CH-PLGA-NPs treated), and Group 4 (CS-coated-CH-loaded-PLGA-NPs treated). 


\subsection{Statistical Analysis}

All the results were calculated statistically as mean \pm SEM (standard error of mean). Student's $t$-test was applied to calculate the unpaired evaluations and their difference was investigated by analysis of variance (ANOVA) in the form of $p$-value.

\section{Results and Discussion}

We selected a hydrophilic drug (catechin hydrate) to encapsulate into PLGA-NPs for this study. Optimized PLGA-NPs were characterized by the particle size, PDI, ZP, EE, DL, and process yield. The observed results indicated that the developed PLGA-NPs, via the double emulsification solvent evaporation method using central composite design software for the optimization of NPs, would be able to successfully encapsulate catechin hydrate for CNS delivery. On the basis of the optimized formula of optimized PLGA-NPs coated with CS to improve their mucoadhesive property and retention time in the nasal region. The developed CS-coated-CH-loaded-PLGA-NPs were further evaluated for $\mathrm{CH}$ release (in vitro), permeation study (ex vivo), and PK and PD study. Our results show that the developed CS-coated-CH-loaded-PLGA-NPs would be successfully coated on CH-PLGA-NPs for intranasal drug delivery systems.

\subsection{Fitting the Model for Experimental Design and the Optimization of CH-PLGA-NPs}

CCD software predicted points were employed for the optimization of independent variables (PLGA, PVA, sonication time, and temperature to obtain the optimum size of particles with good PDI and Zeta potential (Table 1). The experimental ranges for particle size, $Y_{1}(36.00-549.67 \mathrm{~nm}) ;$ PDI, $Y_{2}$ (0.063-0.711); and Zeta potential, $\mathrm{Y}_{3}(-8.12$ to $-33.54 \mathrm{mV})$, are presented in Table 2. We fed all the obtained data for the optimization of dependent variables (DV) into the CCD software which suggested optimized models in the form of polynomial quadratic $(p<0.001)$ design. There were no significant data $(p<0.050)$ found with a "lack of fit" for all three DV values. Predicted $\mathrm{R}^{2}$ values presented in Table 2 for all three DVs were in agreement with "adjusted $R^{2}$ values". Table 3 shows the model fitting of all equations.

$$
\begin{gathered}
\mathrm{Y}_{1}=+305.51+103.76 \mathrm{X}_{1}+78.05 \mathrm{X}_{2}+21.03 \mathrm{X}_{3}-3.03 \mathrm{X}_{4}-2.61 \mathrm{X}_{1} \mathrm{X}_{2}-2.34 \mathrm{X}_{1} \mathrm{X}_{3}-0.9307 \mathrm{X}_{1} \mathrm{X}_{4} \\
-1.83 \mathrm{X}_{2} \mathrm{X}_{3}-0.3182 \mathrm{X}_{2} \mathrm{X}_{4}-0.1371 \mathrm{X}_{3} \mathrm{X}_{4}-0.1496 \mathrm{X}_{1}^{2}-0.4380 \mathrm{X}_{2}^{2}+0.0399 \mathrm{X}_{3}^{2}+0.5933 \mathrm{X}_{4}{ }^{2} \\
\mathrm{Y}_{2}=+0.4250+0.399 \mathrm{X}_{1}+0.0872 \mathrm{X}_{2}+0.0326 \mathrm{X}_{3}+0.0794 \mathrm{X}_{4}-0.0849 \mathrm{X}_{1} \mathrm{X}_{2}-0.0579 \mathrm{X}_{1} \mathrm{X}_{3}+0.0233 \mathrm{X}_{1} \mathrm{X}_{4} \\
+0.0242 \mathrm{X}_{2} \mathrm{X}_{3}-0.0502 \mathrm{X}_{2} \mathrm{X}_{4}-0.0130 \mathrm{X}_{3} \mathrm{X}_{4}-0.00002 \mathrm{X}_{1}^{2}-0.00006 \mathrm{X}_{2}^{2}+0.0001 \mathrm{X}_{3}^{2}+0.0008 \mathrm{X}_{4}^{2} \\
\mathrm{Y}_{3}=-14.63-3.04 \mathrm{X}_{1}-3.62 \mathrm{X}_{2}-0.0764 \mathrm{X}_{3}+1.56 \mathrm{X}_{4}+1.22 \mathrm{X}_{1} \mathrm{X}_{2}+1.25 \mathrm{X}_{1} \mathrm{X}_{3}+1.23 \mathrm{X}_{1} \mathrm{X}_{4}+0.7762 \mathrm{X}_{2} \mathrm{X}_{3} \\
+0.5540 \mathrm{X}_{2} \mathrm{X}_{4}+1.65 \mathrm{X}_{3} \mathrm{X}_{4}-2.00 \mathrm{X}_{1}^{2}-2.92 \mathrm{X}_{2}^{2}-1.70 \mathrm{X}_{3}^{2}-2.71 \mathrm{X}_{4}^{2}
\end{gathered}
$$

Table 3. Summary of regression analysis for responses $Y_{1}$ (particle size in $n m$ ), $Y_{2}$ (PDI), and $Y_{3}$ (Zeta potential).

\begin{tabular}{cccccc}
\hline Quadratic Model & $\mathbf{R}^{\mathbf{2}}$ & Adjusted $\mathbf{R}^{\mathbf{2}}$ & Predicted $\mathbf{R}^{\mathbf{2}}$ & $\mathbf{S D}$ & \% Coefficient of Variation (CV) \\
\hline Response $\left(\mathrm{Y}_{1}\right)$ & 0.9938 & 0.9879 & 0.9833 & 2.52 & 4.02 \\
\hline Response $\left(\mathrm{Y}_{2}\right)$ & 0.9927 & 0.9858 & 0.9805 & 0.0177 & 4.13 \\
\hline Response $\left(\mathrm{Y}_{3}\right)$ & 0.9993 & 0.9986 & 0.9980 & 0.2578 & 1.20 \\
\hline
\end{tabular}

The individual interactive effect for $X_{1}$ (PLGA in $\mathrm{mg}$ ), $\mathrm{X}_{2}$ (\%PVA), $\mathrm{X}_{3}$ (sonication time in seconds, and $\mathrm{X}_{4}$ (temperature, ${ }^{\circ} \mathrm{C}$ ) on particle size is showed in Table 1 as Equation (5). It is evident from the equation that only temperature revealed a negative effect, while the other three showed positive effects; however, a positive effect on particle size $\left(\mathrm{Y}_{1}\right)$ was observed with all three independent variables. Likewise, combination of independent variables showed a -ve effect for PLGA $(\mathrm{mg}) \times \% \mathrm{PVA}\left(\mathrm{X}_{1} \mathrm{X}_{2}\right)$, 
PLGA $(\mathrm{mg}) \times$ sonication time $\left(\mathrm{X}_{1} \mathrm{X}_{3}\right), \operatorname{PLGA}(\mathrm{mg}) \times$ temperature $\left({ }^{\circ} \mathrm{C}\right)\left(\mathrm{X}_{1} \mathrm{X}_{4}\right), \% \mathrm{PVA} \times$ sonication time $\left(X_{2} X_{3}\right), \%$ PVA $\times$ temperature $\left(X_{2} X_{4}\right)$, and sonication time $\times$ temperature $\left(X_{3} X_{4}\right)$, as presented in the three-dimensional plot for particle size range in Figure 1A to F. A gradual reduction in particle size was detected with an increase in sonication time, while a detrimental effect was observed for a decrease in the concentration of PLGA, and the \% of PVA up to a certain limit in the formulation was observed upon a decrease in particle size diameter.

Likewise, a positive increase in PDI was determined with an enhancement in the sonication time, PLGA amount, \% of PVA, and ${ }^{\circ} \mathrm{C}$ temperature in the formulation, as shown in Equation (6) and Figure 2A-F. Furthermore, a positive effect on PDI was revealed as a result of the combined effect of PLGA $(\mathrm{mg}) \times$ temperature $\left({ }^{\circ} \mathrm{C}\right)\left(\mathrm{X}_{1} \mathrm{X}_{4}\right)$ and \%PVA $\times$ sonication time $\left(\mathrm{X}_{2} \mathrm{X}_{3}\right)$, but more negative effects were observed from the combined effect of PLGA $(\mathrm{mg}) \times \%$ PVA $\left(X_{1} X_{2}\right)$, PLGA $(\mathrm{mg}) \times$ sonication time $\left(X_{1} X_{3}\right), \% P V A \times$ temperature $\left(X_{2} X_{4}\right)$, and sonication time $\times$ temperature $\left(X_{3} X_{4}\right)$.

The effect on Zeta potential $(\mathrm{mV})$ from independent variables is shown in Equation (7) and Figure 3A-F, whereby an optimization of Zeta potential was found with an increase in sonication time up to a certain limit, and but contrary results were shown with the amount of PLGA, \%PVA, and temperature, that is, a decrease in their limits up to a certain point, which was not in favor of PDI. PLGA $(\mathrm{mg}) \times$ temperature $\left({ }^{\circ} \mathrm{C}\right)\left(\mathrm{X}_{1} \mathrm{X}_{4}\right), \% \mathrm{PVA} \times$ sonication time $\left(\mathrm{X}_{2} \mathrm{X}_{3}\right)$, PLGA $(\mathrm{mg}) \times \% \mathrm{PVA}$ $\left(X_{1} X_{2}\right)$, PLGA $(m g) \times$ sonication time $\left(X_{1} X_{3}\right), \%$ PVA $\times$ temperature $\left(X_{2} X_{4}\right)$, and sonication time $\times$ temperature $\left(X_{3} X_{4}\right)$, as collectively independent variables, exerted a positive magnitude, which proves a clear dominancy for sonication time on the amount of PLGA, \%PVA, and temperature, and may be attributed to a decrease in particle size with lower PDI, thus favoring an optimum Zeta potential, owing to sonication time.

Constraints were used for independent variables to achieve an optimized formulation (Tables 1 and 4), whereas the independent variables (temperature) were kept in the range followed by the sonication time minimized within the range, whereas constraint applied for the amount of PLGA and \%PVA was "minimized". On the other hand, in between all the dependent variables, "minimize" was marked for particle size with PDI and "maximize" was labeled for Zeta potential.

Table 4. Optimal predicted and optimized batch of CH-PLGA-NPs with independent variables and dependent variables with other characterizations of optimized CH-PLGA-NPs.

\begin{tabular}{|c|c|c|c|c|c|c|c|}
\hline \multirow[t]{2}{*}{ Batch } & \multicolumn{4}{|c|}{ Independent Variables } & \multicolumn{3}{|c|}{ Dependent Variables } \\
\hline & $\mathrm{X}_{1}$ & $\mathrm{X}_{2}$ & $\mathrm{x}_{3}$ & $X_{4}$ & $Y_{1}$ & $\mathrm{Y}_{2}$ & $\mathrm{Y}_{3}$ \\
\hline Predicted & 50.7 & 1.20 & 100 & 28 & 94.14 & 0.108 & -12.61 \\
\hline Optimized & 50.0 & 1.10 & 90 & 25 & $93.46 \pm 3.94$ & $0.106 \pm 0.01$ & $-12.63 \pm 0.08$ \\
\hline $\begin{array}{c}\text { Optimized } \\
\text { Dependent Variables }\end{array}$ & $\begin{array}{c}\text { Actual/Observed } \\
\text { Value }\end{array}$ & $p$-Value & $\begin{array}{l}\text { Entrapment } \\
\text { Efficiency }\end{array}$ & $\begin{array}{c}\text { Drug } \\
\text { Loading }\end{array}$ & $\mathrm{pH}$ & \multicolumn{2}{|c|}{ Process Yield (\%) } \\
\hline Particle Size & $93.46 \mathrm{~nm}$ & $<0.0001$ & \multirow{3}{*}{$73.69 \pm 3.16$} & \multirow{3}{*}{$4.73 \pm 0.11$} & \multirow{3}{*}{$7.4 \pm 0.18$} & \multirow{3}{*}{\multicolumn{2}{|c|}{$76.69 \pm 3.41 \%$}} \\
\hline PDI & 0.106 & $<0.0001$ & & & & & \\
\hline Zeta Potential (mV) & -12.63 & $<0.0001$ & & & & & \\
\hline
\end{tabular}

On the basis of the constraints and quadratic equations for three dependent variables, optimized PLGA-NPs were predicted by CCD with a final composition as follows: PLGA (50.0 mg), 1.10\% PVA, 90 s sonication time, and $25^{\circ} \mathrm{C}$ temperature (Table 4 ).

CCD software suggested the final composition for optimized PLGA-NPs as follows: PLGA (50.0 mg), $1.10 \%$ PVA, $90 \mathrm{~s}$ sonication time, and $25.0{ }^{\circ} \mathrm{C}$ temperature, which was based on the constraints and quadratic equations for three DVs (Table 4). Furthermore, the particle size (93.46 nm), PDI (0.106), and Zeta potential $(-12.63 \mathrm{mV})$ with desirability of 0.9938 were suggested for the optimized CH-PLGA-NPs. Optimized CH-PLGA-NPs were formulated on the basis of the experimental level of nanoformulations to validate their particle size (nm), \%PVA, and Zeta potential (mV), as presented in Table 4 and Figure 4A,B. 

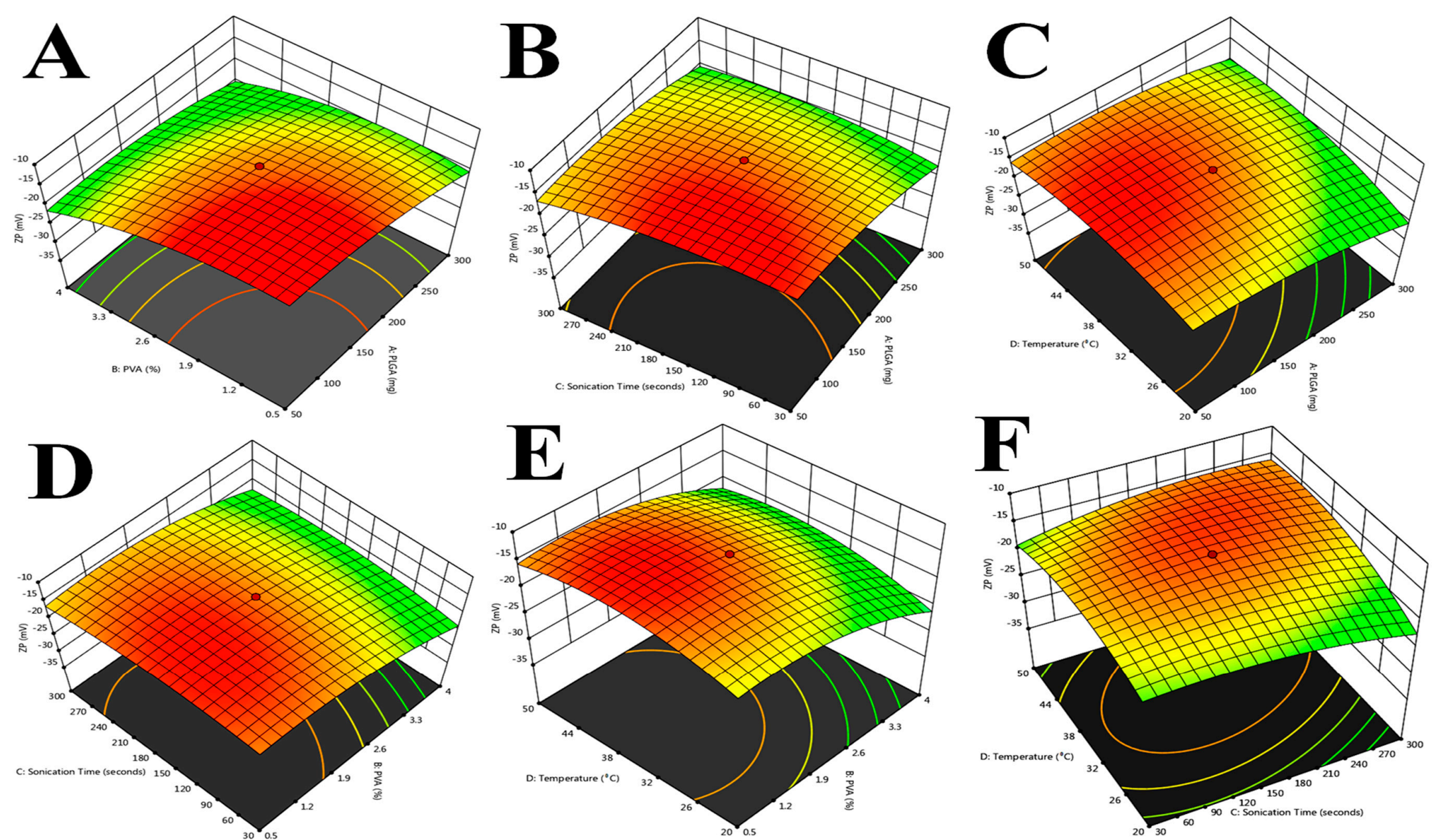

Figure 3. Response surface plot showing the effect of independent variables on Zeta potential (ZP). (A). Zeta potential, PVA (\%), PLGA; (B). Zeta potential, sonication time, PLGA; (C). Zeta potential, temperature $\left({ }^{\circ} \mathrm{C}\right)$, PLGA; (D). Zeta potential, sonication time, PVA (\%); (E). Zeta potential, temperature, PVA (\%); (F). Zeta potential, temperature, sonication time. 


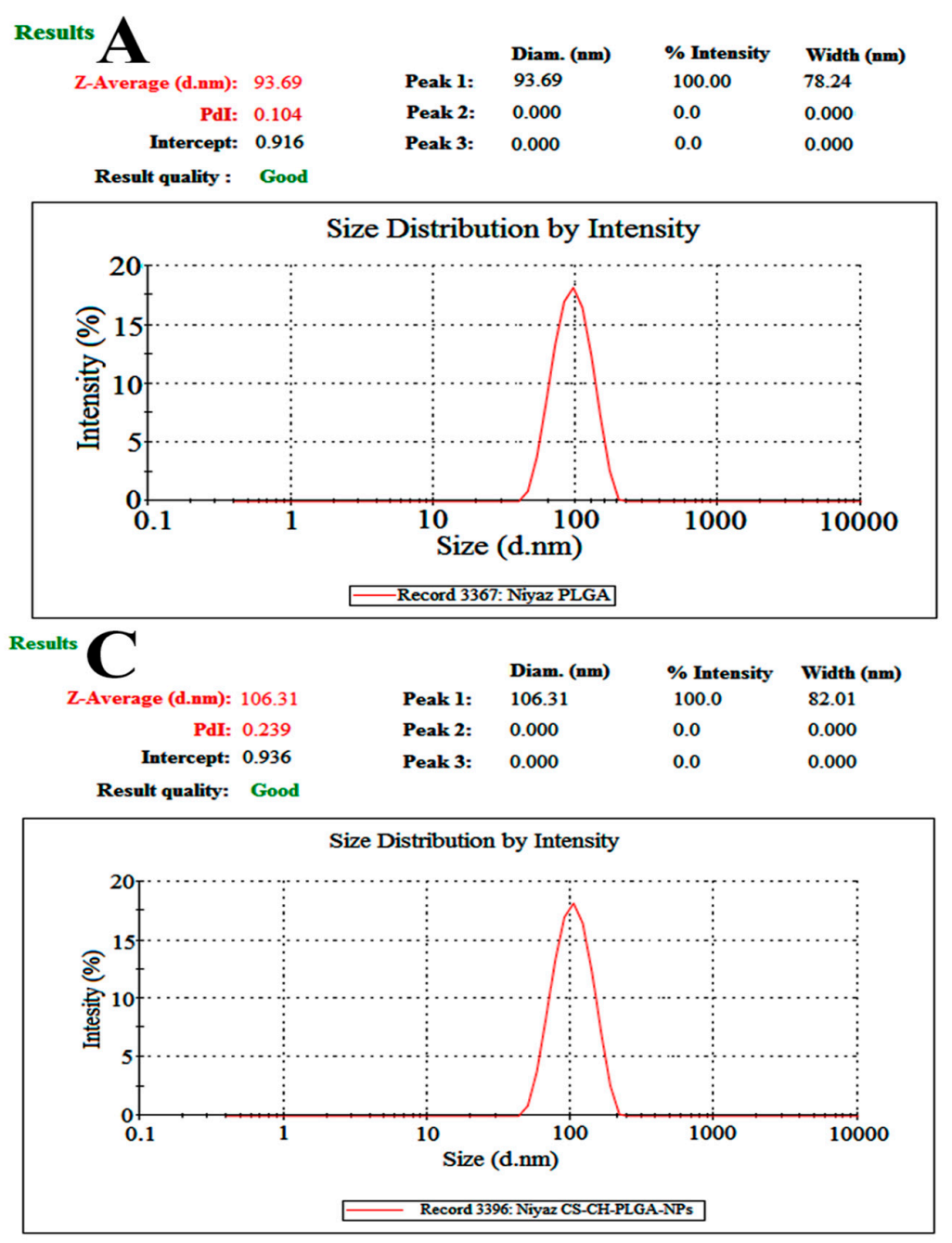

\section{Results B}

Zeta Potential (mv): -12.39 Peak 1: -12.39 Zeta Deviation $(\mathrm{mV}): 3.61$ Peak 2: 0.00

Conductivity $(\mathrm{mS} / \mathrm{cm}): 0.116$

Result quality : Good

\section{Zeta Potential Distribution}

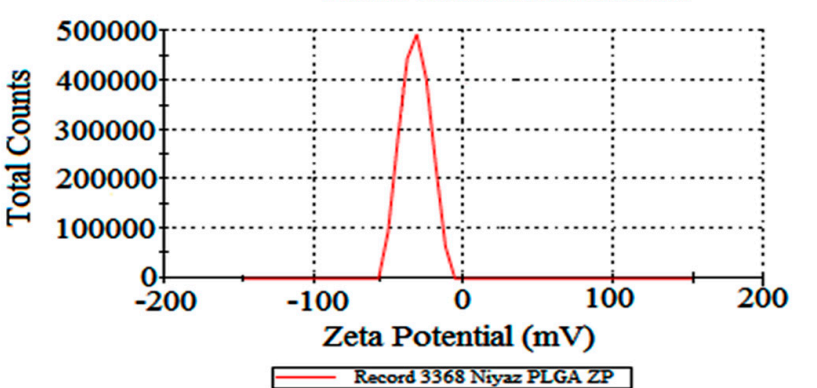

Results D

Zeta Potential (mV): 21.64 Peak 1 Mean (mV) Area (\%) Width (mV) $\begin{array}{lllll} & \text { Peak 3: } & 0.000 & 0.0 & 0.000 \\ & & 0.0 & 0.000\end{array}$

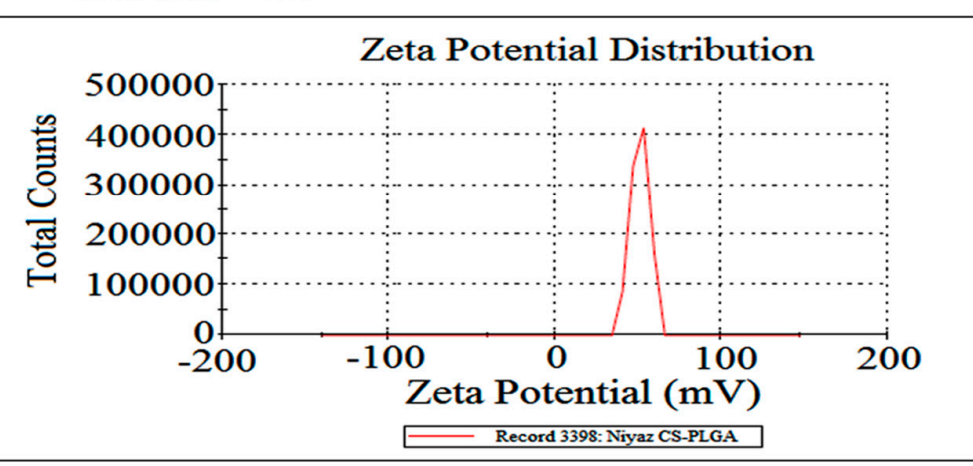

Figure 4. Dynamic light scattering techniques for determining the particle size distribution of CH-loaded-PLGA-NPs' globule size (A) and Zeta potential (B), as well as CS-coated-CH-loaded-PLGA-NPs' particle size (C) and zeta potential (D) images. 
For the improvement of brain bioavailability for antiepileptic efficiency, the uptake of cells was increased by the preparation of coating with chitosan on optimized CH-PLGA-NPs in different \%age CS concentrations, as shown in Table 5. A modified and previously reported Ahmad et al., 2017b CS-coating technique for the preparation of CS-coated-optimized CH-PLGA-NPs to the brain targeted $\mathrm{CH}$ delivery. All the coated NPs were characterized on the basis of $\mathrm{ZP}$, PDI with their particle size range in which all the particles were observed $<200.0 \mathrm{~nm}$, and smallest PDI $(<0.380)$ (Table 5). In addition, the ultrasonication process helped to reduce the size of the particles at the nanometer-size range with a narrow PDI. The sizes of the PLGA-NPs were measured as $93.46 \pm 3.94 \mathrm{~nm}$, where loading of the catechin hydrate did not show any significant increase in size of the NPs. However, the initial particle size for optimized CH-loaded-PLGA-NPs was $93.46 \pm 3.94 \mathrm{~nm}$, which was significantly increased to $106.31 \pm 2.91 \mathrm{~nm}$ and $142.43 \pm 3.94 \mathrm{~nm}$ after application of a different percentage $(2 \%$ and $4 \%)$ of CS-coating on the CH-PLGA-NPs (Table 5, Figure 4C) [28,45]. As reported before, the particle size was increased slightly owing to the coating of a high molecular weight of CS on PLGA $[28,49]$. In addition, an enhancement of the particle size owing to CS-coating on NPs was also seen. On the other hand, this enhancement of the particle size may be because of a greater amount of polymer addition via CS-coating [50]. Furthermore, the amount of polymer was increased, which produced a more viscous dispersed phase. Therefore, it resulted in an increase in the particle size for NPs [51]. PDI produced a value $<0.380$, which means the distribution of particle size inside the suspension is lower, while ZP gave values of $21.64 \pm 1.04$ and $24.34 \pm 1.59 \mathrm{mV}$ for $2 \%$ and $4 \%$ CS-coating on CH-PLGA-NPs, respectively (Figure 4D). When CS was coated on CH-PLGA-NPs, a +ve ZP was produced because of the presence of the amine group in the CS structure [52,53]. However, in all cases, formulated nanoparticles were recorded with $<0.380 \mathrm{PDI}$, indicating the monodisperse nature of the nanoparticles. The surface charge of the formulated PLGA NPs was found to be almost constant, near to slightly negative $(-12.63 \pm$ $0.08 \mathrm{mV}$, Figure 4B, for CH-PLGA-NPs). Coating of the NPs, in comparison, showed a significant alteration of the surface charge towards a positive scale to $21.64 \pm 1.04$ and $24.34 \pm 1.59 \mathrm{mV}$ for $2 \%$ and $4 \%$ CS coating on CH-PLGA-NPs, respectively [53].

Table 5. Chitosan coating above selected optimized CH-loaded-PLGA-NPs tried $1 \%$ and $2 \%$ CS concentration.

\begin{tabular}{|c|c|c|c|c|c|c|c|}
\hline Formulation Code & $\begin{array}{l}\text { Chitosan } \\
(\%)\end{array}$ & $\mathrm{pH}$ & $\begin{array}{c}\text { Mean } \\
\text { Particle Size } \\
(\mathrm{nm}) \pm \text { SD }\end{array}$ & $\begin{array}{c}\text { Polydispersity } \\
\text { Index (PDI) } \pm \text { SD }\end{array}$ & $\begin{array}{c}\text { Zeta } \\
\text { Potential } \\
(\mathrm{mV})\end{array}$ & $\begin{array}{c}\text { Entrapment } \\
\text { Efficiency } \\
(\mathrm{EE} \%) \pm \mathrm{SD}\end{array}$ & $\begin{array}{c}\text { Drug } \\
\text { Loading } \\
(\mathrm{DL} \%) \pm \text { SD }\end{array}$ \\
\hline $\begin{array}{l}\text { CS-coated-optimized-C } \\
\text { H-loaded-PLGA-NPs } 1\end{array}$ & 2 & 7.4 & $106.31 \pm 2.91$ & $0.239 \pm 0.008$ & $\begin{array}{c}21.64 \pm \\
1.04\end{array}$ & $80.36 \pm 4.01$ & $5.98 \pm 0.36$ \\
\hline $\begin{array}{l}\text { CS-coated-optimized-C } \\
\text { H-loaded-PLGA-NPs } 2\end{array}$ & 4 & 7.4 & $142.43 \pm 3.94$ & $0.364 \pm 0.023$ & $\begin{array}{c}24.34 \pm \\
1.59\end{array}$ & $81.66 \pm 4.61$ & $6.87 \pm 0.49$ \\
\hline
\end{tabular}

CH: catechin hydrate, PLGA: poly(lactic-co-glycolic acid), NPs: nanoparticles, CS: chitosan, SD: standard deviation, PDI: polydispersity index, DL: drug loading, EE: entrapment efficiency.

PLGA was used as a polymer to formulate the polymeric nanoparticles, whereas PVA was incorporated to stabilize the formulation. PVA is a widely used stabilizer to formulate PLGA NPs $[28,45]$, where the binding of PVA with PLGA is facilitated by the interpenetration of PLGA and PVA molecules during the development of NPs. Being a copolymer, PVA consists of poly(vinyl alcohol) and poly(vinyl acetate), with the characteristics of a block copolymer, where the vinyl part displays a hydrophobic nature. This hydrophobic segment of PVA is known to penetrate the organic phase during formulation development, while removal of organic solvent from the polymeric matrix results in entrapment of the PVA segment within the PLGA polymeric matrix [54]. Ultrasonication of the course emulsion reduced the size of the dispersed phase, and thereby the particles of the nanocarrier were found to be uniform in characteristics, within the size range of $93.46 \pm 3.94 \mathrm{~nm}$. Selection of $\mathrm{CH}$ and polymer contents with proper control of processing parameters was conducted as described in our previous articles [28,54], and during the formulation development of $\mathrm{CH}$-loaded PLGA NP, we were able to obtain the size of the optimized particles with the desired mean diameter. The PDIs of the 
formulations are found to be low, and thus did not show any variations in batches prepared during the entire research period, indicating the formation of unimodal particles. Coating of the particles with CS has shown a significant $(p<0.05)$ increase in the size of the particles; however, such a change in size did not alter the mean PDI when compared with uncoated particles, which indicates that the process of formulation development does not result in agglomeration of the particles after CS coating.

\section{2. $\%$ EE and $\% D L$ Examination}

The average particle size with PDI at different compositions of PLGA polymer is presented in the Table 2. However, the optimized CH PLGA NPs and 2\% CS coated optimized CH-PLGA-NPs were $93.46 \pm 3.94 \mathrm{~nm}$ and $106.31 \pm 2.91 \mathrm{~nm}$ in particle size, with $-12.63 \pm 0.08 \mathrm{mV}$ and $21.64 \pm 1.04 \mathrm{mV}$ ZP, respectively. Finally, the concentrations of PLGA polymer showed a small impact on the amount of $\mathrm{CH}$ entrapment for NPs. CH-loaded-PLGA-NPs showed a maximum \%EE with the developed NPs of $2 \%$ and $4 \%$ CS-coated, equal to $80.36 \pm 4.01 \%$ and $81.66 \pm 4.61 \%$, with an optimal \%DL, that is, $5.98 \pm 0.36 \%$ and $6.87 \pm 0.49 \%$, respectively. The effects of $\% E E$ and $\% D L$ of polymers on CS-coated-opt-CH-PLGA-NPs were also shown, as presented in Table 5. In addition, \%EE and \%DL were dependent on the percentage use of polymer, which resulted in an enhancement in \%EE from $80.36 \pm 4.01 \%$ to $81.66 \pm 4.61 \%$, as well as in $\%$ DL from $5.98 \pm 0.36 \%$ to $6.87 \pm 0.49 \%$, for $2 \%$ and $4 \%$ CS-coating on PLGA NPs, respectively. CS-CH-PLGA-NPs displayed significantly maximum percentages of DL and EE when compared with other types of NPs formulations. In this way, we can characterize the presence of PVA and the surface of CS on the NPs.

Finally, it is concluded that $\mathrm{CH}$ adsorbed the surface of NPs because of the electrostatic interaction between positively-charged chitosan and negatively-charged hydroxyl $(-\mathrm{OH})$ of $\mathrm{CH}[28,45]$. A $21.64 \mathrm{mV}$ ZP has the stability of the optimized CS-CH-PLGA-NPs (Figure 4D). CS-CH-PLGA-NPs present a +ve charge on their surface, which helps the mucoadhesion, and an extended residence time, followed by the reduction of mucociliary clearance of optimized NPs from the nasal-mucosa [27,28].

\subsection{Determination of Outer Surface Texture of NPs' Analysis}

In all cases of $\mathrm{CH}$-loaded NPs tested for morphology and the morphological evaluation, spherical particles with a smooth surface are indicated, as depicted in the SEM and TEM micrographs (Figure 5). PLGA NPs can be aggregated owing to the process of drying with their maximum surface energy. The size of NPs was analysed by DLS technology, whereas the real diameter of NPs after drying was analysed by TEM and SEM. Spherical-shaped CS-CH-PLGA-NPs were shown by TEM (Figure 5B). TEM microscopic viewfinder was divided into four quadrants and analysed all the particles size ranges, that is, less than $110.0 \mathrm{~nm}$. All the determinations were found to be approximately the same as each other.
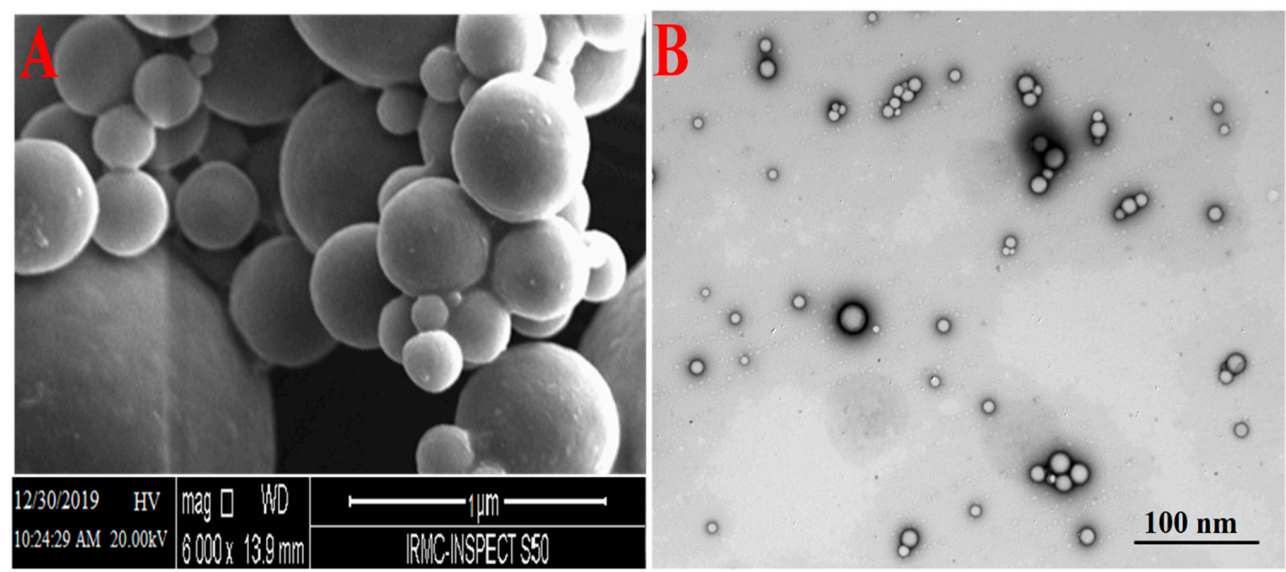

Figure 5. Scanning electron microscopy (SEM) (A) and transmission electron microscopy (TEM) (B) images of CS-coated-CH-loaded-PLGA-NPs. 


\subsection{Differential Scanning Calorimetry (DSC)}

The DSC thermograms of pure catechin (CH); polymer (PLGA); polyvinyl alcohol (PVA); a physical mixture of $\mathrm{CH}, \mathrm{PVA}$, and PLGA; freeze-dried $\mathrm{CH}$-loaded-optimized polymer (PLGA)-NPs; pure chitosan; and CS-coated-CH-loaded-optimized polymeric PLGA-NPs, respectively, are represented in Figure 6. (+)-Catechin presents two peaks in the temperature range of $75-150{ }^{\circ} \mathrm{C}$ linked to water loss, and an endothermic peak at $175.3^{\circ} \mathrm{C}$ linked to anhydrous catechin melting, which is very close to or the same as the reported melting point of $175.0^{\circ} \mathrm{C}$, followed by its decomposition above $200^{\circ} \mathrm{C}$. Similarly, the physical mixture of $\mathrm{CH}, \mathrm{PVA}$, and PLGA exhibited the characteristic peaks of all of these. However, the $\mathrm{CH}$ sharp peak was absent in $\mathrm{CH}$-loaded-PLGA-NPs. This indicates that catechin was completely entrapped in the CH-loaded-PLGA-NPs. A broad peak of PLGA and PLGA-NPs was shown between 45 and $55^{\circ} \mathrm{C}$ (Figure 6) [28,54]. DSC thermogram of CS gave an exothermic broad peak at $311.5^{\circ} \mathrm{C}$, which appeared again in DSC thermograms of CS-coated CH-loaded-PLGA-NPs at $311.7^{\circ} \mathrm{C}$. The chitosan peak was recognized again in the thermogram of the CS-coated-PLGA-NPs (Figure 6), because that coated on the PLGA-NPs and one smaller peak of PLGA at $52.5^{\circ} \mathrm{C}$ also shown, possibly owing to the smaller \%CS amount, correlate to that percentage of PLGA, but the CH-DSC thermogram peak was also absent in the CS-CH-PLGA-NPs (Figure 6) [28,54].

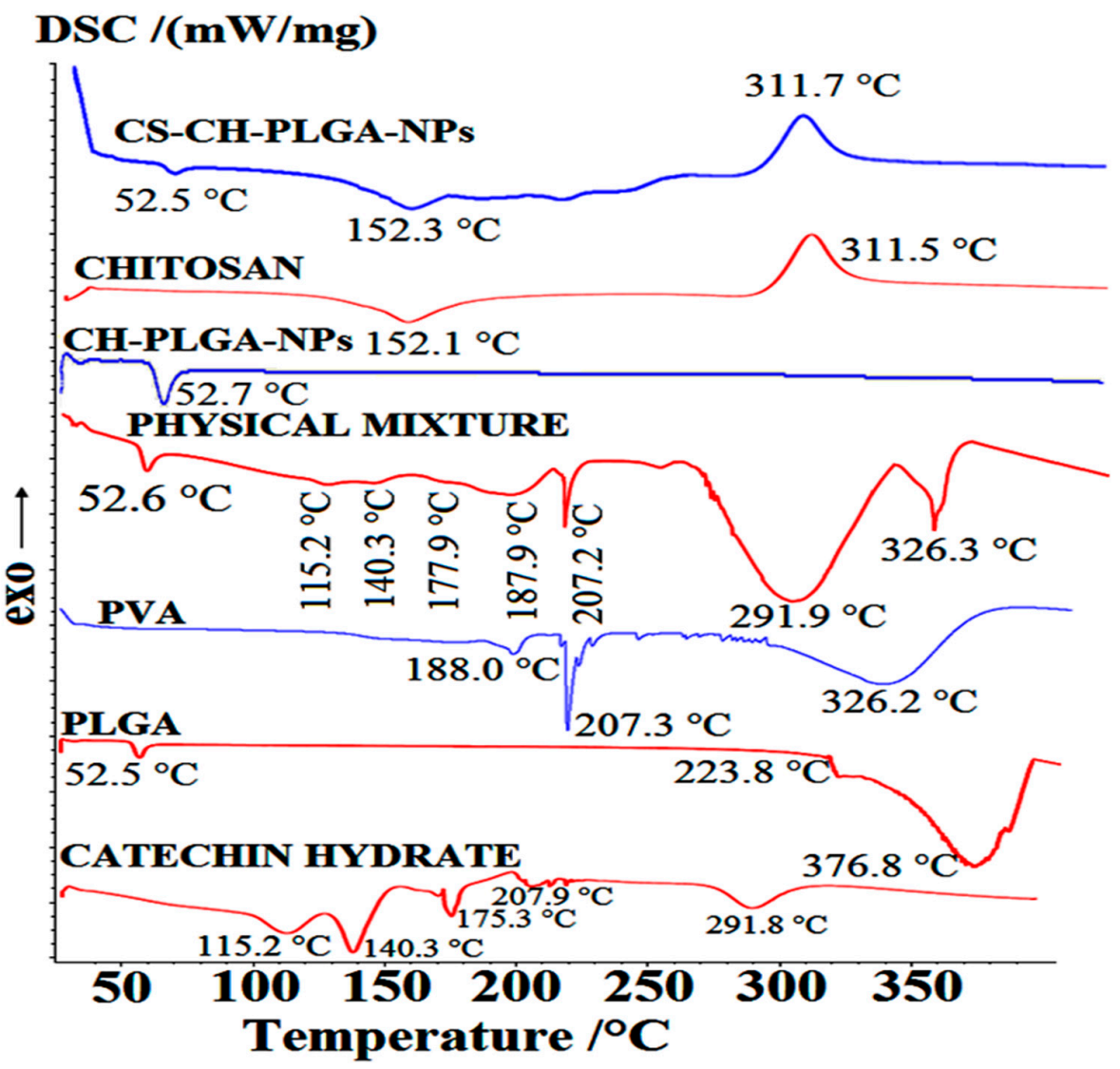

Figure 6. The differential scanning calorimetry (DSC) thermograms of pure catechin $(\mathrm{CH})$; polymer (PLGA); polyvinyl alcohol (PVA); a physical mixture of CH, PVA, and PLGA; freeze-dried $\mathrm{CH}-$ loaded-optimized polymeric (PLGA)-NPs; pure chitosan; and CS-coated-CH-loaded-optimized polymeric PLGA-NPs.

\subsection{ATR Analysis Based on FTIR}

Pure catechin hydrate $(\mathrm{CH})$, PVA, PLGA-NPs, CH-loaded-PLGA-NPs, chitosan, and chitosan-coated-CH-loaded-PLGA-NPs were evaluated via FTIR spectrophotometer, which is presented in Figure 7. Pure catechin hydrate $(\mathrm{CH})$, PVA, PLGA-NPs, CH-loaded-PLGA-NPs, 
chitosan, and chitosan-coated-CH-loaded-PLGA-NPs were evaluated via ATR. ATR is a tool that works on the basis of FT-IR technology, in which our optimized NPs' surfaces can be analysed qualitatively or quantitatively [54]. Characteristic IR peaks of catechin were observed at 3341.23 (phenolic hydroxyl group), 1608.75, 1519.29, 1458.83, (phenyl ring), 1143.96, and 1027.99 (stretching vibration of $\mathrm{C}-\mathrm{O}-\mathrm{C}) \mathrm{cm}^{-1}$. The PLGA spectrum displayed stretching peaks of $-\mathrm{C}=\mathrm{O}$ at 1746.53 $\mathrm{cm}^{-1}$ and $\mathrm{C}-\mathrm{H}$ bending at $850-1470 \mathrm{~cm}^{-1}$. PLGA responded at $2950.22 \mathrm{~cm}^{-1}$ owing to the linear $\mathrm{CH}_{2}$ stretching and at $1746.53 \mathrm{~cm}^{-1}$ owing to the ester bond. For PVA, the characteristic absorption peaks are at $3313.52 \mathrm{~cm}^{-1}\left(\mathrm{O}-\mathrm{H}\right.$ stretching), $2936.09 \mathrm{~cm}^{-1}$ (asymmetric stretching of $\left.\mathrm{CH}_{2}\right), 2911.57$ $\mathrm{cm}^{-1}$ (symmetric stretching of $\left.-\mathrm{CH}_{2}\right), 1567.93 \mathrm{~cm}^{-1}$ (owing to water absorption), $1427.11 \mathrm{~cm}^{-1}\left(-\mathrm{CH}_{2}\right.$ bending), $1321.16 \mathrm{~cm}^{-1}\left(\delta(\mathrm{OH})\right.$, rocking with $\mathrm{CH}$ wagging), $1087.92 \mathrm{~cm}^{-1}(-\mathrm{C}-\mathrm{O}$ stretching with $-\mathrm{OH}$ bending) (PVA amorphous sequence), $945.48 \mathrm{~cm}^{-1}\left(-\mathrm{CH}_{2}\right.$ rocking), and $842.76 \mathrm{~cm}^{-1}$ (stretching of C-C). CH-PLGA-NPs achieved all the distinctive peaks of PLGA-NPs. However, the CH-distinctive peak inside the CH-loaded-PLGA-NPs showed the diminished peaks. All these nanomaterial surfaces data for optimized NPs were analysed by ATR technology. On the basis of the evaluation of these results, it was concluded that $\mathrm{CH}$ was present inside the core of CH PLGA NPs. ATR spectra of CS showed a distinctive band at $3376.71 \mathrm{~cm}^{-1}$, that is, a clear indication of an N-H bond overlapped with $\mathrm{O}-\mathrm{H}$ bond streching. The $\mathrm{C}-\mathrm{H}$ stretching-vibration and $\mathrm{N}-\mathrm{H}$ bending-vibration were designated at $2891.36 \mathrm{~cm}^{-1}$ and $1651.44 \mathrm{~cm}^{-1}$, respectively. The characteristic peaks of the catechin and CS-coated-CH-loaded-PLGA-NPs were present in the spectrum with no extra peaks for their opposite interaction. However, in the case of CS-coated-CH-loaded-PLGA-NPs, the peaks of the catechin were indicated to be diminished, representing a small interaction between the catechin and the polymer; thus, catechin hydrate presence inside the core of NPs can be recommended (Figure 7) [54].

\subsection{In Vitro $\mathrm{CH}$ Release Evaluation}

$\mathrm{CH}$ was released as a cumulative pattern for $\mathrm{CH}-\mathrm{S}$, that is, $87.63 \pm 3.98 \%$, and CH-PLGA-NPs, that is, $67.28 \pm 5.03 \%$, in addition to biodegradable polymeric, that is, CS-CH-PLGA NPs, $81.34 \pm 4.02$ in 1 to $24 \mathrm{~h}$, correspondingly (Figure 8A). CS-CH-PLGA-NPs exhibited a biphasic release as follows: $40.11 \pm 3.21 \%$ drug release in the initial $2 \mathrm{~h}$, followed by a sustained release for the remaining $\mathrm{CH}$; this burst release behavior may be because of more solubility in dissolution media along with a quick release of the drug from the NPs' surface (drug present more at the surface of NPs). CS-coated NPs released a biphasic $\mathrm{CH}$ release pattern like $40.11 \pm 3.21 \%$ initially up to $2.0 \mathrm{~h}$, after which it showed a sustained release pattern for the remaining percentage of $\mathrm{CH}$. The burst release pattern may be the result of the presence of a higher quantity of $\mathrm{CH}$ on the NPs' surface. This allows fast release from the highest \% solubility in dissolution media. The most important part here is that $\mathrm{CH}$ was encapsulated inside the core of NPs, which showed a sustained release pattern. The maximum crystalline nature of PLGA NPs' structure and smaller PVA permeability of water were most important for the smaller rate of degradation with their sustained release of $\mathrm{CH}[28,53]$. On other side, if CS was added to coat on the NPs, $\mathrm{CH}$ enhanced the rate of slow release, which can be indicated by the higher permeability of water via the CS surface [34]. CH was released at a maximum via optimized NPs containing hydrophilic glycolide units of PLGA-NPs, which enhanced the release up to $12.0 \mathrm{~h}$, after which $\mathrm{CH}$ was released in a sustained form. The hydrophilic nature of PLGA was enhanced, which is responsible for the enhancement of water permeability of optimized NPs' surface, resulting in an enhanced quantity of $\mathrm{CH}$ release [28,54]. Furthermore, PLGA showed smaller hydrophilicity in comparison with CS, which produces a higher hydration of optimized NPs' matrix, and thus a maximum quantity of $\mathrm{CH}$ was released $[28,34,54]$. 


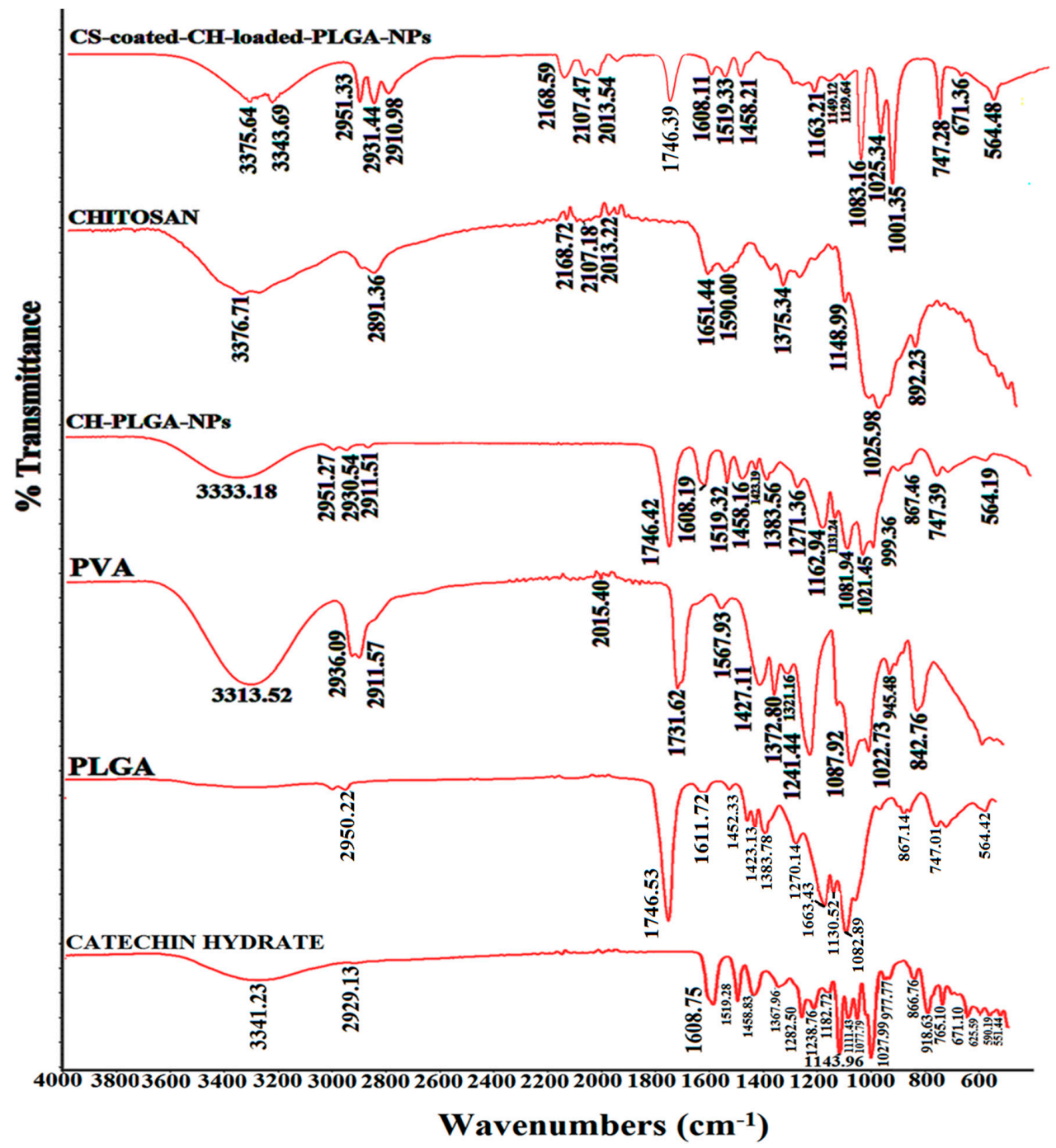

Figure 7. Different Fourier transform infrared spectroscopy (FTIR) spectra with an attenuated total reflection (ATR) attachment of pure catechin hydrate (CH), PVA, PLGA-NPs, CH-loaded-PLGA-NPs, chitosan, and chitosan-coated-CH-loaded-PLGA-NPs.
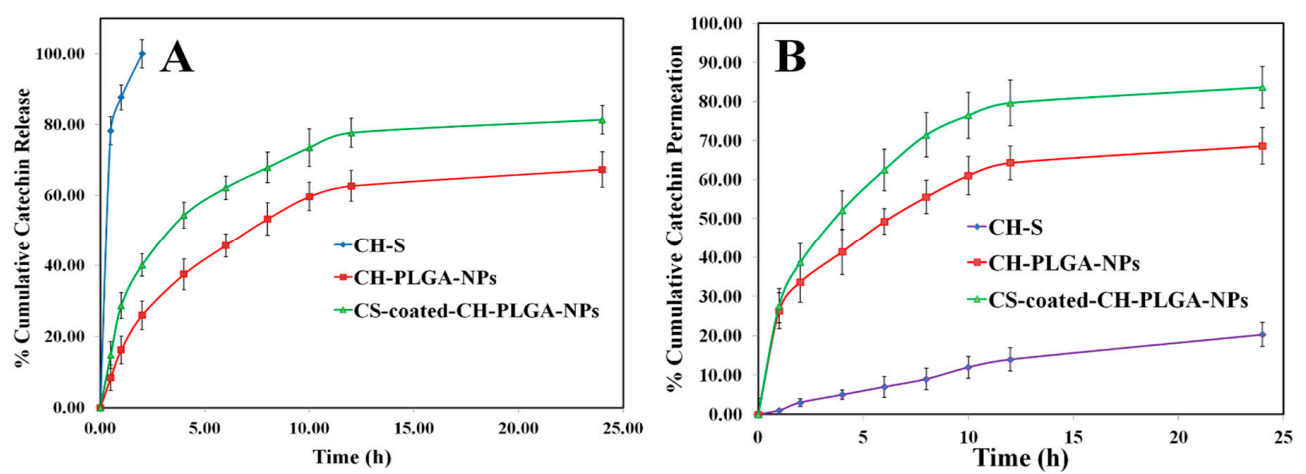

Figure 8. (A) In vitro release profile of CS-S, CH-loaded-PLGA-NPs, and chitosan-coated-CHloaded-PLGA-NPs performed using the dialysis bag method, revealing the sustained release pattern of CH-loaded-PLGA-NPs and Chitosan-coated-CH-loaded-PLGA-NPs (mean \pm SD, $n=3$ ). (B) Ex vivo permeation profiles of developed chitosan-coated-CH-loaded-PLGA-NPs as compared with $\mathrm{CH}$-loaded-PLGA-NPs and pure $\mathrm{CH}-\mathrm{S}$ through goat nasal mucosa. 


\subsection{A Permeation (Ex Vivo) Evaluation via Nasal Mucosa}

Pure CH-S showed less permeation compared with CH PLGA NPs and CS-CH-PLGA NPs (Figure 8B). The permeation profile was found to be more significant for CS-CH-PLGA NPs $(p<0.001)$ compared with CS-CH-PLGA NPs $(p<0.01)$ and CH-S. This means CS-CH-PLGA NPs increased the permeation activity of CS. The permeation was found to be highest with $>83.64 \pm 5.33 \%$ in $24.0 \mathrm{~h}$ for CS-CH-PLGA NPs, whereas CH-PLGA-NPs and CH-S were only $68.64 \pm 4.66 \%$ and $20.34 \pm 2.99 \%$, respectively (Figure $8 \mathrm{~B}$ ). Catechin hydrate improved their permeation because of the positively-charged $-\mathrm{NH}_{2}$-group on the $\mathrm{CS}$ carbon two-position, which interacted with the negatively-charged cell membranes. Similarly, mucosal epithelial cells were responsible for their tight junction mechanism endorsement [28]. Pure CH-S has much less permeability owing to their hydrophilic nature, which is a strong justification. The lipophilic nature of drugs has a higher permeability via skin or nasal mucosa, as stated by Richter and Keipert [55]. CS-CH-PLGA NPs with hydrophobic surface and particle size $<200 \mathrm{~nm}$ size easily penetrate the biological membrane. At this time, we concluded on the basis of the above results that, as they contain the smallest size of NPs with maximum percentage yield and optimal \% of EE plus LC, which is responsible for the higher permeation profile, the CS-CH-PLGA-NPs will give better results for in vivo activity.

\subsection{Bioanalysis by UHPLC/MS/MS}

Figures 9 and 10 exhibit MS and MS/MS scans of CH and IS MS and MS/MS spectra of CH at the time of method development. The developed chromatograms of different matrixes are shown in Figure 11A,B; extracted plasma and brain homogenate $(\mathrm{BH})$ of $\mathrm{CH}$ are shown in Figure $11 \mathrm{C}, \mathrm{D}$; followed by extracted plasma and $\mathrm{BH}$ of quercetin shown in Figure 11E,F. Mean recovery of $\mathrm{CH}$ from $\mathrm{BH}$ and plasma $(n=6)$ was shown to be $>80.17 \%$. All proposed matrixes of $\mathrm{CH}$ showed an excellent linearity with a range $1.0-1000 \mathrm{ng} / \mathrm{mL}$, that is, $r^{2}>0.998$. Further, LOD and LOQ were found to be 0.894 and $1.00 \mathrm{ng} / \mathrm{mL}$, respectively. The selectivity of all developed chromatograms for all different matrixes of $\mathrm{CH}$ was proven. (Coefficient of variation) $\% \mathrm{CV}(0.72-3.81 \%, 0.39-4.90 \%$, and $0.59-4.08 \%$ ) was found, whereas the \% accuracy (97.03-99.41\%, 93.07-98.62\%, and 96.04-98.71\%) is exhibited for brain homogenate (BH), Plasma PL, and lungs homogenate (LH) of all QCs in Table 6. All the different QC levels stabled in different storage conditions like freeze thaw, long-term, post-processing, and bench-top are displayed in Table 7 [28,56,57]. For the validation of parameters calculations, we used the formulas mentioned in Table 8.

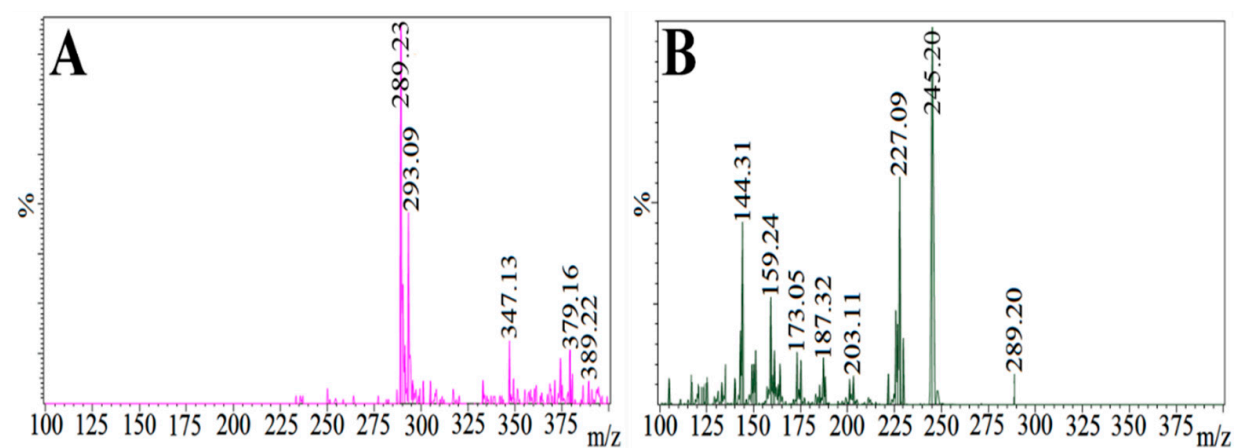

Figure 9. Mass spectrum of $(\mathbf{A})$ catechin hydrate $(\mathrm{CH})$ parent ion (protonated precursor $[\mathrm{M}-\mathrm{H}]^{-}$ions at $\mathrm{m} / \mathrm{z} 289.23$ ) and $(\mathbf{B})$ catechin hydrate $(\mathrm{CH})$ product ion (major fragmented product ion at $\mathrm{m} / \mathrm{z} 245.20$ ) showing fragmentation transitions. 
Table 6. Validation: precision and accuracy data for catechin hydrate $(\mathrm{CH})$ in different biomatrixes. LOQQC, lower limit of quantification for quality control; LQC, lower QC; MQC, medium QC; HQC, high QC.

\begin{tabular}{|c|c|c|c|c|c|c|c|c|c|}
\hline \multirow[b]{2}{*}{ Biomatrix } & \multirow{2}{*}{$\begin{array}{c}\text { Quality } \\
\text { Controls } \\
\text { Samples }\end{array}$} & \multirow{2}{*}{$\begin{array}{l}\text { Theoretical Concentration } \\
\left(\mathrm{ng} \mathrm{mL}^{-1}\right) \text { or }\left(\mathrm{ng} \mathrm{g}^{-1}\right)\end{array}$} & \multicolumn{3}{|c|}{ Intra-Batch Precision } & \multicolumn{3}{|c|}{ Inter-Batch Precision } & \multirow{2}{*}{$\begin{array}{l}\text { Recovery } \\
(\%)\end{array}$} \\
\hline & & & $\begin{array}{l}\text { Observed Concentration } \\
\left(\mathrm{ng} \mathrm{mL}^{-1}\right) \text { or }\left(\mathrm{ng} \mathrm{g}^{-1}\right) \pm \text { S.D. }\end{array}$ & $\begin{array}{l}\text { Accuracy } \\
(\%)\end{array}$ & $\begin{array}{l}\text { Precision } \\
\text { (\%C.V.) }\end{array}$ & $\begin{array}{c}\text { Observed Concentration } \\
\left(\mathrm{ng} \mathrm{mL}^{-1}\right) \text { or }\left(\mathrm{ng} \mathrm{g}^{-1}\right) \pm \text { S.D. }\end{array}$ & $\begin{array}{l}\text { Accuracy } \\
(\%)\end{array}$ & $\begin{array}{l}\text { Precision } \\
\text { (\%C.V.) }\end{array}$ & \\
\hline \multirow{4}{*}{$\begin{array}{l}\text { Brain } \\
\text { Homogenate }\end{array}$} & LOQQC & 1.01 & $0.99 \pm 0.03$ & 98.02 & 3.03 & $0.98 \pm 0.04$ & 97.03 & 2.90 & 81.47 \\
\hline & LQC & 2.90 & $2.85 \pm 0.09$ & 98.28 & 3.16 & $2.84 \pm 0.11$ & 97.93 & 2.44 & 83.48 \\
\hline & MQC & 410.00 & $407.61 \pm 11.36$ & 99.41 & 2.79 & $403.17 \pm 12.54$ & 98.33 & 1.42 & 80.17 \\
\hline & HQC & 800.00 & $789.67 \pm 18.64$ & 98.47 & 3.81 & $784.69 \pm 19.21$ & 98.09 & 0.72 & 81.38 \\
\hline \multirow{4}{*}{$\begin{array}{l}\text { Lungs } \\
\text { Homogenate }\end{array}$} & LOQQC & 1.01 & $0.98 \pm 0.04$ & 97.03 & 4.08 & $0.97 \pm 0.06$ & 96.04 & 2.34 & 80.25 \\
\hline & LQC & 2.90 & $2.83 \pm 0.11$ & 97.59 & 3.89 & $2.81 \pm 0.16$ & 96.90 & 1.04 & 81.67 \\
\hline & MQC & 410.00 & $404.71 \pm 13.02$ & 98.71 & 3.22 & $402.37 \pm 14.17$ & 98.14 & 0.59 & 82.49 \\
\hline & HQC & 800.00 & $779.25 \pm 19.61$ & 97.41 & 2.52 & $775.43 \pm 20.18$ & 96.93 & 0.39 & 81.52 \\
\hline \multirow{4}{*}{ Plasma } & LOQQC & 1.01 & $0.96 \pm 0.03$ & 95.05 & 3.13 & $0.94 \pm 0.04$ & 93.07 & 2.32 & 80.57 \\
\hline & LQC & 2.90 & $2.86 \pm 0.14$ & 98.62 & 4.90 & $2.85 \pm 0.15$ & 98.28 & 1.94 & 82.61 \\
\hline & MQC & 410.00 & $402.33 \pm 11.42$ & 98.13 & 2.84 & $401.34 \pm 12.69$ & 97.89 & 0.66 & 83.46 \\
\hline & $\mathrm{HQC}$ & 800.00 & $778.67 \pm 21.64$ & 97.33 & 2.78 & $774.18 \pm 22.37$ & 96.77 & 0.39 & 84.51 \\
\hline
\end{tabular}

Values (mean \pm SD) are derived from six replicates. 
Table 7. Validation: stability data for catechin hydrate $(\mathrm{CH})$ in different biomatrixes.

\begin{tabular}{|c|c|c|c|c|c|c|c|c|c|}
\hline \multirow{2}{*}{$\begin{array}{l}\text { Exposure } \\
\text { Condition }\end{array}$} & \multicolumn{3}{|c|}{ LQC $\left(2.90 \mathrm{ng} / \mathrm{mL}\right.$ or $\left.\mathrm{ng} \mathrm{g}^{-1}\right)$} & \multicolumn{3}{|c|}{ MQC (410.00 ng/mL or $\left.\mathrm{ng} \mathrm{g}^{-1}\right)$} & \multicolumn{3}{|c|}{ HQC (800.00 ng/mL or $\left.\mathrm{ng} \mathrm{g}^{-1}\right)$} \\
\hline & $\begin{array}{c}\text { Brain } \\
\text { Homogenate }\end{array}$ & $\begin{array}{c}\text { Lungs } \\
\text { Homogenate }\end{array}$ & Plasma & $\begin{array}{c}\text { Brain } \\
\text { Homogenate }\end{array}$ & $\begin{array}{c}\text { Lungs } \\
\text { Homogenate }\end{array}$ & Plasma & $\begin{array}{c}\text { Brain } \\
\text { Homogenate }\end{array}$ & $\begin{array}{c}\text { Lungs } \\
\text { Homogenate }\end{array}$ & Plasma \\
\hline \multicolumn{10}{|c|}{ Long-term stability; recovery $(\mathrm{ng})$ after storage $\left(-80^{\circ} \mathrm{C}\right)$} \\
\hline Previous day & $2.84 \pm 0.11$ & $2.86 \pm 0.10$ & $2.85 \pm 0.10$ & $406.35 \pm 11.36$ & $407.11 \pm 10.08$ & $406.93 \pm 9.36$ & $794.36 \pm 13.38$ & $792.48 \pm 12.93$ & $789.45 \pm 13.64$ \\
\hline 30th Day & $\begin{array}{c}2.81 \pm 0.10 \\
(98.94 \%)\end{array}$ & $\begin{array}{c}2.83 \pm 0.14 \\
(98.95 \%)\end{array}$ & $\begin{array}{c}2.82 \pm 0.11 \\
(98.95 \%)\end{array}$ & $\begin{array}{c}400.24 \pm 9.21 \\
(98.50 \%)\end{array}$ & $\begin{array}{c}399.25 \pm 8.96 \\
(98.07 \%)\end{array}$ & $\begin{array}{c}400.21 \pm 9.28 \\
(98.35 \%)\end{array}$ & $\begin{array}{c}777.43 \pm 12.97 \\
(97.87 \%)\end{array}$ & $\begin{array}{c}781.64 \pm 11.67 \\
(98.63 \%)\end{array}$ & $\begin{array}{c}776.78 \pm 12.32 \\
(98.40 \%)\end{array}$ \\
\hline \multicolumn{10}{|c|}{ Freeze-thaw stress; recovery (ng) after freeze-thaw cycles $\left(-80^{\circ} \mathrm{C}\right.$ to $\left.25^{\circ} \mathrm{C}\right)$} \\
\hline Pre-Cycle & $2.87 \pm 0.09$ & $2.89 \pm 0.09$ & $2.88 \pm 0.09$ & $407.14 \pm 10.22$ & $406.15 \pm 9.34$ & $405.33 \pm 9.37$ & $792.47 \pm 13.57$ & $790.45 \pm 12.31$ & $789.49 \pm 11.64$ \\
\hline First Cycle & $\begin{array}{c}2.84 \pm 0.11 \\
(98.95 \%)\end{array}$ & $\begin{array}{c}2.87 \pm 0.08 \\
(99.31 \%)\end{array}$ & $\begin{array}{c}2.85 \pm 0.07 \\
(98.96 \%)\end{array}$ & $\begin{array}{c}403.25 \pm 9.24 \\
(99.04 \%)\end{array}$ & $\begin{array}{c}402.34 \pm 10.04 \\
(99.06 \%)\end{array}$ & $\begin{array}{c}401.24 \pm 9.01 \\
(98.99 \%)\end{array}$ & $\begin{array}{c}784.19 \pm 11.38 \\
(98.96 \%)\end{array}$ & $\begin{array}{c}781.44 \pm 12.10 \\
(98.86 \%)\end{array}$ & $\begin{array}{c}777.41 \pm 12.48 \\
(98.47 \%)\end{array}$ \\
\hline Second Cycle & $\begin{array}{c}2.81 \pm 0.10 \\
(97.91 \%)\end{array}$ & $\begin{array}{c}2.85 \pm 0.09 \\
(98.62 \%)\end{array}$ & $\begin{array}{c}2.84 \pm 0.08 \\
(98.61 \%)\end{array}$ & $\begin{array}{c}400.14 \pm 9.04 \\
\quad(98.28)\end{array}$ & $\begin{array}{c}399.28 \pm 9.03 \\
(98.31 \%)\end{array}$ & $\begin{array}{c}396.32 \pm 8.94 \\
(97.78 \%)\end{array}$ & $\begin{array}{c}771.58 \pm 12.02 \\
(97.36 \%)\end{array}$ & $\begin{array}{c}773.24 \pm 11.64 \\
(97.82 \%)\end{array}$ & $\begin{array}{c}761.58 \pm 14.64 \\
(96.46 \%)\end{array}$ \\
\hline Third Cycle & $\begin{array}{c}2.79 \pm 0.08 \\
(97.21 \%)\end{array}$ & $\begin{array}{c}2.82 \pm 0.07 \\
(97.58 \%)\end{array}$ & $\begin{array}{c}2.82 \pm 0.07 \\
(97.92 \%)\end{array}$ & $\begin{array}{c}397.16 \pm 10.04 \\
(97.55 \%)\end{array}$ & $\begin{array}{c}392.14 \pm 11.04 \\
(96.55 \%)\end{array}$ & $\begin{array}{c}390.18 \pm 9.01 \\
(96.26 \%)\end{array}$ & $\begin{array}{c}764.28 \pm 12.09 \\
(96.44)\end{array}$ & $\begin{array}{c}763.24 \pm 13.08 \\
(96.56 \%)\end{array}$ & $\begin{array}{c}753.49 \pm 10.39 \\
(95.44 \%)\end{array}$ \\
\hline \multicolumn{10}{|c|}{ Bench top stability; recovery $(\mathrm{ng})$ at room temperature $\left(25^{\circ} \mathrm{C}\right)$} \\
\hline $0 \mathrm{~h}$ & $2.88 \pm 0.07$ & $2.89 \pm 0.09$ & $2.88 \pm 0.07$ & $408.01 \pm 11.01$ & $405.97 \pm 10.13$ & $406.48 \pm 10.17$ & $791.41 \pm 11.92$ & $793.46 \pm 13.01$ & $791.61 \pm 12.07$ \\
\hline $24 \mathrm{~h}$ & $\begin{array}{c}2.85 \pm 0.08 \\
(96.96 \%)\end{array}$ & $\begin{array}{c}2.87 \pm 0.07 \\
(99.31 \%)\end{array}$ & $\begin{array}{c}2.83 \pm 0.04 \\
(98.26 \%)\end{array}$ & $\begin{array}{c}399.97 \pm 10.16 \\
(98.03 \%)\end{array}$ & $\begin{array}{c}399.46 \pm 9.63 \\
(98.40 \%)\end{array}$ & $\begin{array}{c}399.94 \pm 9.64 \\
(99.39 \%)\end{array}$ & $\begin{array}{c}779.94 \pm 12.06 \\
(98.55 \%)\end{array}$ & $\begin{array}{c}778.92 \pm 11.64 \\
(98.17 \%)\end{array}$ & $\begin{array}{c}780.06 \pm 13.08 \\
(98.54 \%)\end{array}$ \\
\hline \multicolumn{10}{|c|}{ Post-processing stability; recovery (ng) after storage in auto sampler $\left(4^{\circ} \mathrm{C}\right)$} \\
\hline $0 \mathrm{~h}$ & $2.85 \pm 0.07$ & $2.87 \pm 0.06$ & $2.88 \pm 0.09$ & $404.36 \pm 8.94$ & $406.14 \pm 9.43$ & $407.36 \pm 10.00$ & $790.34 \pm 11.56$ & $789.64 \pm 11.64$ & $791.25 \pm 12.32$ \\
\hline $4 \mathrm{~h}$ & $\begin{array}{c}2.82 \pm 0.06 \\
(98.95 \%)\end{array}$ & $\begin{array}{c}2.84 \pm 0.07 \\
(98.95 \%)\end{array}$ & $\begin{array}{c}2.83 \pm 0.06 \\
(98.26 \%)\end{array}$ & $\begin{array}{c}398.99 \pm 9.02 \\
(98.67 \%)\end{array}$ & $\begin{array}{c}399.04 \pm 8.81 \\
(98.25 \%)\end{array}$ & $\begin{array}{c}401.03 \pm 9.34 \\
(98.45 \%)\end{array}$ & $\begin{array}{c}779.86 \pm 12.34 \\
(98.67 \%)\end{array}$ & $\begin{array}{c}774.64 \pm 12.08 \\
(98.10 \%)\end{array}$ & $\begin{array}{c}776.34 \pm 10.05 \\
(98.12 \%)\end{array}$ \\
\hline
\end{tabular}

Values (mean \pm SD) are derived from six replicates. Figures in parenthesis represent analyte concentration (\%) relative to time zero. Theoretical contents: LQC: $2.90 \mathrm{ng} \mathrm{mL}^{-1}$; MQC: 410.00 $\mathrm{ng} \mathrm{mL}{ }^{-1}$; and HQC: $800.00 \mathrm{ng} \mathrm{mL}^{-1}$. 


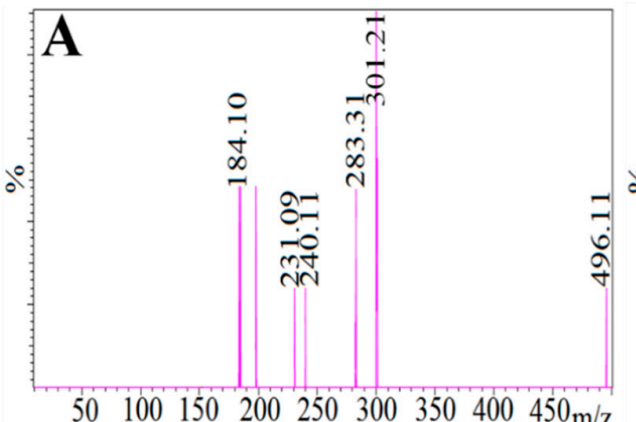

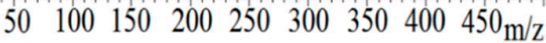

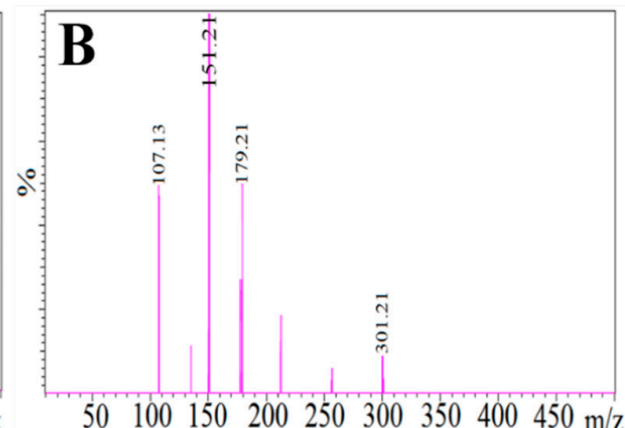

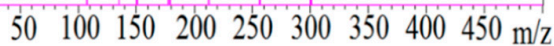

Figure 10. Mass spectrum of, (A) quercetin (IS) precursor ion (protonated precursor $[\mathrm{M}-\mathrm{H}]^{-}$ions at $\mathrm{m} / \mathrm{z} 301.21$ and (B) internal standard (IS) product ion (major fragmented product ions at $\mathrm{m} / \mathrm{z} 151.21$ ) showing fragmentation transitions.
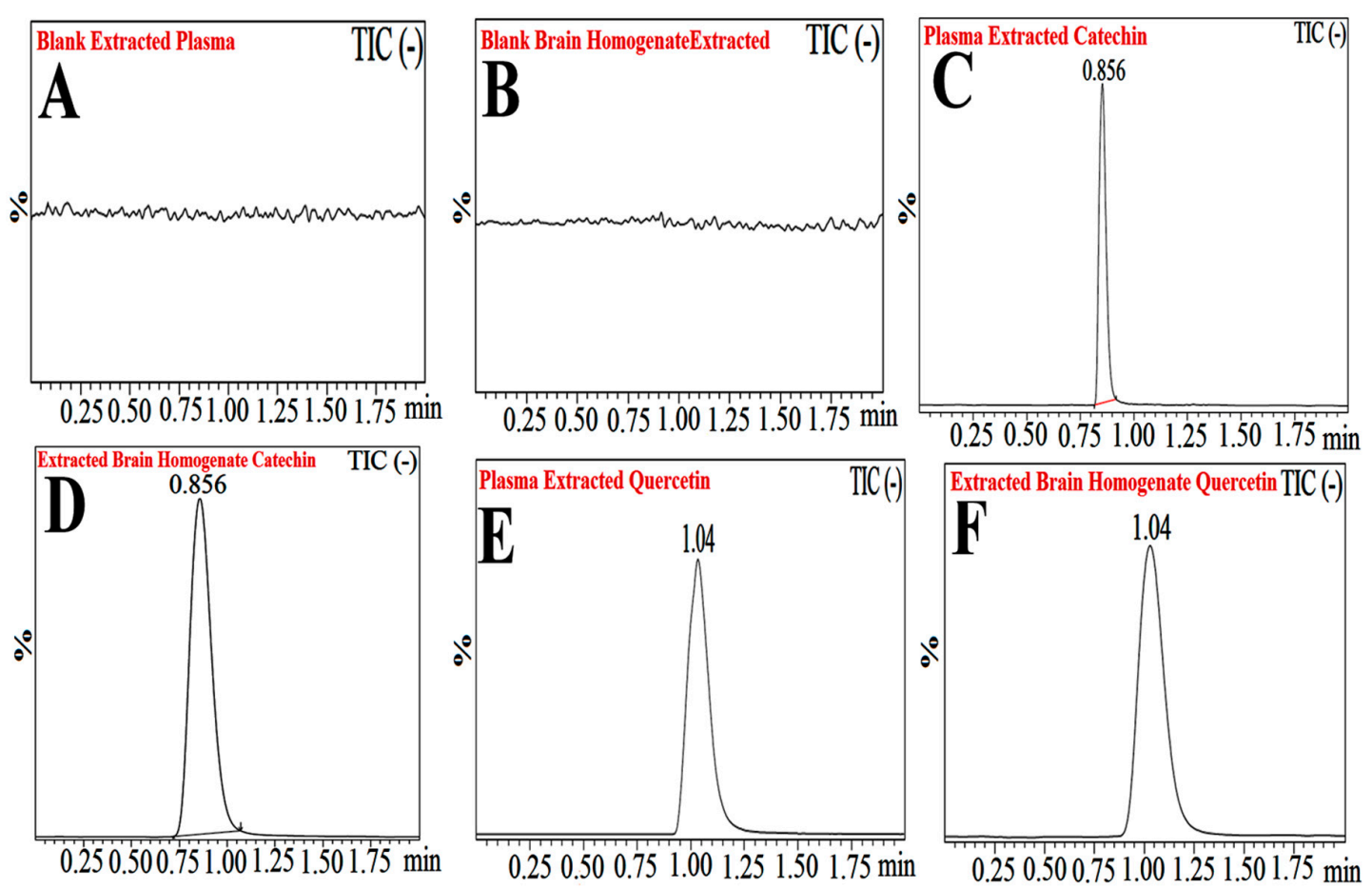

Figure 11. Typical chromatograms of extracted blank plasma (A), extracted blank brain homogenate (B), plasma extracted catechin hydrate $(\mathrm{CH})(\mathrm{C})$, extracted brain homogenate catechin hydrate $(\mathrm{CH})(\mathrm{D})$, plasma extracted quercetin (IS) (E), and extracted brain homogenate quercetin (IS) (F).

Table 8. Definitions and formulas used in the calculations.

\begin{tabular}{|c|}
\hline Accuracy $(\%)=$ Mean value of $[($ mean observed concentration $) /($ theoretical concentration $)] \times 100$; \\
\hline $\begin{aligned} \text { Precision }(\%) \text { : Coefficient of variance }(\text { percentage })= & \text { standard deviation divided by mean concentration found } \\
& \times 100 ;\end{aligned}$ \\
\hline $\begin{array}{c}\text { Recovery }(\%)=\text { Mean value of }(\text { peak height }(\mathrm{mV}) \text { obtained from extracted biological sample }) /(\text { peak height }(\mathrm{mV}) \\
\text { obtained from aqueous sample }) \times 100 .\end{array}$ \\
\hline
\end{tabular}

\subsection{Evaluation of PK Parameters}

The compared $\mathrm{PK}$ parameters including $\mathrm{C}_{\max }$ and $\mathrm{T}_{\max }$ exhibited brain $\mathrm{CH}$ concentration versus time for single i.v. and i.n. doses of CH-S, CH-PLGA-NPs, and CS-CH-PLGA-NPs in Wistar rats, while the trapezoidal method was used (Figure 12). For $\mathrm{CH}-\mathrm{S}, \mathrm{C}_{\max }$ of $44.23 \pm 7.04$ (i.v.) and $81.68 \pm 10.13 \mathrm{ng} / \mathrm{mL}$ (i.n.) was found; for CH-PLGA-NPs, an enhanced $C_{\max }$ of $98.36 \pm 19.55 \mathrm{ng} / \mathrm{mL}$ (i.v.) and $623.36 \pm 24.21 \mathrm{ngmL}^{-1}$ (i.n.) was found; while for CS-CH-PLGA-NPs, an enhanced $\mathrm{C}_{\max }$ 
of $126.48 \pm 17.61 \mathrm{ngmL}^{-1}$ (i.v.) and $996.24 \pm 44.24 \mathrm{ngmL}^{-1}$ (i.n.) was exhibited $\left({ }^{*} p<0.1,{ }^{* *} p<0.01\right.$, and $\left.{ }^{* * *} p<0.001\right)$ (Table 9). Therefore, a elevated i.n. $\mathrm{AUC}_{0-\mathrm{t}}(977.32 \pm 33.14 \mathrm{ng} \mathrm{h} / \mathrm{mg})$ for $\mathrm{CH}-\mathrm{S}$, $\mathrm{AUC}_{0-\mathrm{t}}(7785.90 \pm 83.64 \mathrm{ng} \mathrm{h} / \mathrm{mg})$ for CH-PLGA-NPs, and $\mathrm{AUC}_{0-\mathrm{t}}(12,444.50 \pm 139.25 \mathrm{ng} \mathrm{h} / \mathrm{g})$ for CS-CH-PLGA-NPs was observed $\left({ }^{*} p<0.1,{ }^{* *} p<0.01\right.$, and $\left.{ }^{* * *} p<0.001\right)$, respectively, for highly significant data of CS-CH-PLGA-NPs as compared with $\mathrm{CH}-\mathrm{S}$ by i.n., as a result of the enhanced $\mathrm{C}_{\max }$ with the delayed elimination rate. Likewise, comparative bioavailability of CS-CH-PLGA-NPs, $\mathrm{CH}-\mathrm{PLGA}-\mathrm{NPs}$, and $\mathrm{CH}-\mathrm{S}$ was enhanced for the brain when we applied statistics for i.n. application. There is a clear indication of nose to brain targeting, as reported in the previous research study $[28,34,54]$.

Table 9. Pharmacokinetics (PKs) of catechin hydrate after i.n. and i.v. administration to rats at the dose of $10 \mathrm{mg} \mathrm{kg}^{-1}$ in the brain, lungs, and plasma $(n=6$, mean $\pm \mathrm{SD})$. AUC, area under curve.

\begin{tabular}{|c|c|c|c|c|c|c|}
\hline $\begin{array}{l}\text { Formulation } \\
\text { Administration }\end{array}$ & Samples & $\mathrm{Cmax}(\mathrm{ng} / \mathrm{mL} \mathrm{g})$ & $\mathrm{T}_{\max }$ & $t_{1 / 2}(h)$ & $\operatorname{Ke}\left(h^{-1}\right)$ & $\begin{array}{c}\mathrm{AUC}_{0-\mathrm{t}} \\
\text { (ng min/mL g) }\end{array}$ \\
\hline \multirow{3}{*}{$\mathrm{CH}-\mathrm{S}$ (i.n.) } & Brain & $81.68 \pm 10.13$ & 2.00 & $15.25 \pm 2.06$ & $0.04544 \pm 0.0006$ & $977.32 \pm 33.14$ \\
\hline & Lungs & $28.64 \pm 3.09$ & 2.00 & $21.77 \pm 2.19$ & $0.03184 \pm 0.00011$ & $373.85 \pm 16.47$ \\
\hline & Plasma & $32.02 \pm 2.63$ & 0.50 & $8.23 \pm 3.10$ & $0.08420 \pm 0.0009$ & $170.48 \pm 18.43$ \\
\hline \multirow{3}{*}{$\mathrm{CH}-\mathrm{S}$ (i.v.) } & Brain & $44.23 \pm 7.04$ & 2.00 & $11.16 \pm 0.39$ & $0.06210 \pm 0.0009$ & $395.26 \pm 19.47$ \\
\hline & Lungs & $95.43 \pm 18.14$ & 2.00 & $9.19 \pm 0.81$ & $0.07540 \pm 0.00051$ & $958.79 \pm 34.64$ \\
\hline & Plasma & $1141.54 \pm 83.45$ & 0.50 & $4.69 \pm 0.29$ & $0.14767 \pm 0.0018$ & $3167.33 \pm 55.67$ \\
\hline \multirow{3}{*}{ CH-PLGA-NPs (i.n.) } & Brain & $623.36 \pm 24.21$ & 2.00 & $24.71 \pm 4.59$ & $0.02806 \pm 0.00006$ & $7785.90 \pm 83.64$ \\
\hline & Lungs & $106.97 \pm 11.97$ & 2.00 & $11.00 \pm 1.01$ & $0.06303 \pm 0.00011$ & $1033.42 \pm 44.67$ \\
\hline & Plasma & $56.78 \pm 4.64$ & 2.00 & $8.26 \pm 0.97$ & $0.08391 \pm 0.00008$ & $409.41 \pm 25.94$ \\
\hline \multirow{3}{*}{ CS-CH-PLGA-NPs (i.n.) } & Brain & $996.24 \pm 44.24$ & 2.00 & $21.81 \pm 3.94$ & $0.03178 \pm 0.00008$ & $12444.50 \pm 139.25$ \\
\hline & Lungs & $121.64 \pm 18.45$ & 2.00 & $11.21 \pm 2.88$ & $0.06184 \pm 0.0008$ & $1187.01 \pm 31.04$ \\
\hline & Plasma & $99.67 \pm 10.18$ & 2.00 & $9.33 \pm 0.94$ & $0.07427 \pm 0.00013$ & $936.04 \pm 86.79$ \\
\hline \multirow{3}{*}{ CH-PLGA-NPs (i.v.) } & Brain & $98.36 \pm 19.55$ & 2.00 & $15.91 \pm 3.06$ & $0.04355 \pm 0.00010$ & $1170.58 \pm 28.57$ \\
\hline & Lungs & $109.94 \pm 7.98$ & 2.00 & $11.52 \pm 2.97$ & $0.06016 \pm 0.0005$ & $1091.68 \pm 34.67$ \\
\hline & Plasma & $757.54 \pm 33.16$ & 1.00 & $16.65 \pm 1.06$ & $0.04162 \pm 0.0007$ & $9430.18 \pm 189.67$ \\
\hline \multirow{3}{*}{ CS-CH-PLGA-NPs (i.v.) } & Brain & $126.48 \pm 17.61$ & 2.00 & $67.83 \pm 5.47$ & $0.01022 \pm 0.00006$ & $1959.57 \pm 79.68$ \\
\hline & Lungs & $136.48 \pm 15.97$ & 2.00 & $62.03 \pm 2.91$ & $0.01117 \pm 0.0010$ & $1974.57 \pm 44.89$ \\
\hline & Plasma & $1064.43 \pm 96.43$ & 1.00 & $15.83 \pm 1.06$ & $0.04378 \pm 0.0006$ & $12948.59 \pm 277.13$ \\
\hline $\mathrm{CH}-\mathrm{S}$ (i.n.) & Brain/Plasma & 2.55 & 4.00 & 1.85 & 0.54 & 5.73 \\
\hline CH-S (i.v.) & Brain/Plasma & 0.039 & 4.00 & 2.38 & 0.42 & 0.13 \\
\hline CH-PLGA-NPs (i.n.) & Brain/Plasma & 10.98 & 1.00 & 2.99 & 0.34 & 19.02 \\
\hline CH-PLGA-NPs (i.v.) & Brain/Plasma & 0.13 & 2.00 & 0.96 & 1.05 & 0.12 \\
\hline CS-CH-PLGA-NPs (i.n.) & Brain/Plasma & 10.00 & 1.00 & 2.34 & 0.43 & 13.29 \\
\hline CS-CH-PLGA-NPs (i.v.) & Brain/Plasma & 0.13 & 2.00 & 4.29 & 0.23 & 0.15 \\
\hline \multicolumn{7}{|c|}{ Comparative Bioavailability * $\left(\mathrm{AUC}_{\mathrm{i} . \mathrm{n} .} / \mathrm{AUC}_{\mathrm{i} . \mathrm{v} .}\right) ;(\%)$} \\
\hline Formulations & \multicolumn{2}{|c|}{$\mathrm{CH}-\mathrm{S}$} & \multicolumn{2}{|c|}{ CH-PLGA-NPs } & \multicolumn{2}{|c|}{ CS-CH-PLGA-NPs } \\
\hline Blood & \multicolumn{2}{|r|}{5.38} & \multicolumn{2}{|r|}{4.34} & \multicolumn{2}{|c|}{7.23} \\
\hline Brain & \multicolumn{2}{|c|}{$247.26^{*}$} & \multicolumn{2}{|c|}{$665.13^{* *}$} & \multicolumn{2}{|c|}{$1063.11^{* * *}$} \\
\hline
\end{tabular}

* Parameters are derived using mean \pm SEM values of six different estimations. For the $p$-value: ${ }^{* *}(p<0.001)$,

** $(p<0.01)$, and * $(p<0.05)$.

Release of the entrapped therapeutic agent $(\mathrm{CH})$ from the colloidal delivery system is highly necessary to produce the intended physiological response, where this release can effectively be modulated through alteration of the physicochemical characteristics of the medium. As the formulated CS-coated CH-PLGA is intended to deliver the entrapped drug inside the brain by the i.n. route, the release study of the formulations was performed at $\mathrm{pH}=7.4$, which approximately corresponds to the $\mathrm{pH}$ of the brain cellular compartments. A biodegradable polymer released a drug, for example, $\mathrm{CH}$, by various mechanisms: polymeric pores re-adsorbed on their surface, diffusion, CS-coated-PLGA NPs desorbed on their surface, or degradation and erosion of polymeric surface (Md et al., 2013). 
CS-coated-PLGA NPs released CH very fast at first, that is, $28.64 \%$ in $1.0 \mathrm{~h}$, and afterwards released it in a sustained manner up to $24.0 \mathrm{~h}$. On the other side, $\mathrm{CH}-\mathrm{S}$ released very fast, that is, $87.63 \%$ up to $1.0 \mathrm{~h}$, but in the case of CS-coated-PLGA NPs, $\mathrm{CH}$ was released very fast at first owing to the burst release, and after that, $\mathrm{CH}$ was released in a sustained manner from the outer surface of optimized NPs (Figure 8A).

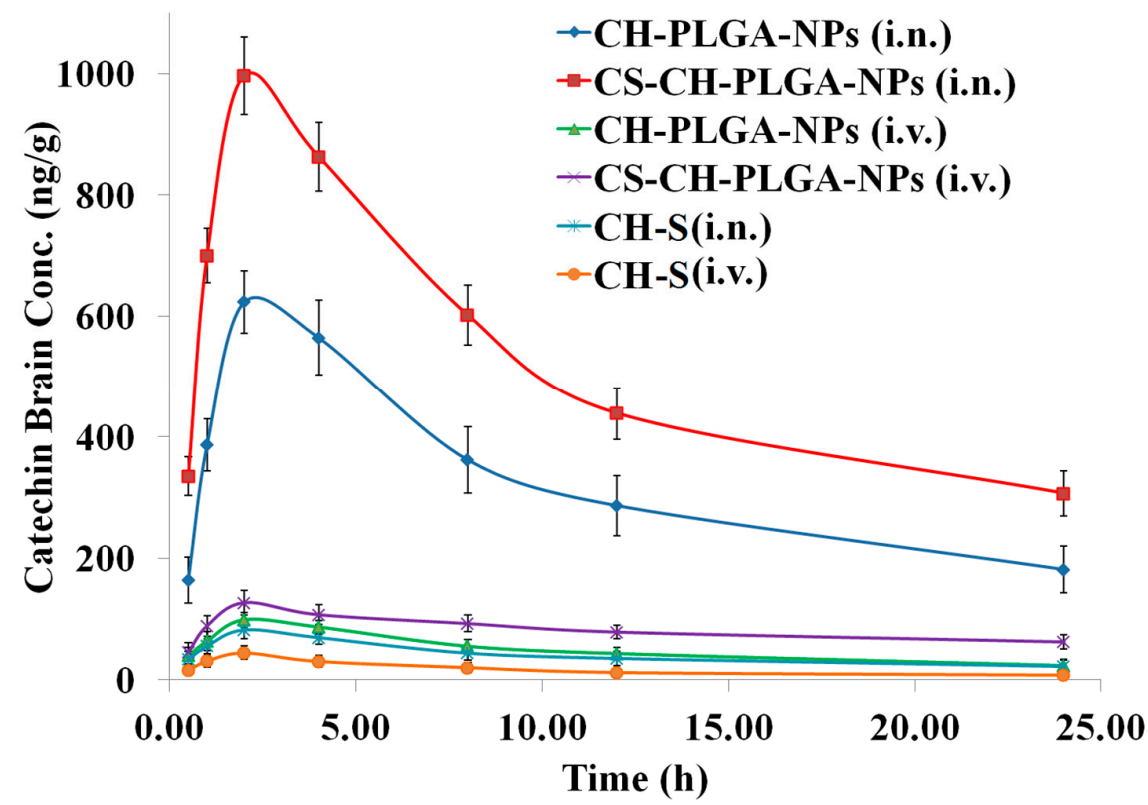

Figure 12. Pharmacokinetic profiles of catechin hydrate $(\mathrm{CH})$ concentration in the brain at different time intervals after administration of optimized different nanoformulations compared with pure catechin hydrate $(\mathrm{CH})$.

Bioavailability of the brain increased via the burst release of $\mathrm{CH}$ from CS-coated-PLGA NPs to produce $\mathrm{CH}$ for epilepsy treatment. The Higuchi model showed $\mathrm{r}^{2}=0.986$ for kinetic release, which also gave a clear indication that $\mathrm{CH}$ was released through the diffusion and swelling methods in a controlled manner [58]. Goat nasal mucosa was used for $\mathrm{CH}$ permeation study of CS-coated-PLGA NPs $(<0.001)$ as compared with CH-PLGA NPs $(<0.01)$ and pure-CH-S, which showed higher enhancement of $\mathrm{CH}$ permeation by CS-coating [34]. Higher permeation of CS CH-PLGA NPs was found because of the smaller size of NPs as well as the interaction of the $-\mathrm{NH}_{2}$ group of CS containing a +ve charge and nasal mucosa containing a -ve charge on their surface [27]. CS contained an oligosaccharide chain of mucin that showed mucoadhesive nature of CS without the loaded drug and CS CH-PLGA NPs. CS-mucoadhesive potency is more suitable relative to others owing to the interaction of CS, that is, the mucin content is much higher [27].

\subsection{Evaluation of Epilepsy Treatment}

\subsubsection{Catechin Hydrate Effect on ICES Test}

The selected dose of $10.0 \mathrm{mg} \mathrm{kg}^{-1} \mathrm{~b}$. wt. taken for CS CH-PLGA NPs $(p<0.001)$ and CH PLGA NPs $(p<0.01)$ was highly significant at the time of ICES evaluation as compared with CH-S, as on the other side, a highly significant protection $(p<0.001, p<0.01$, and $p<0.05)$ correspondingly was also found when compared with the normal saline group, that is, the control (Figure 13).

\subsubsection{Treatment of PTZ-Induced Seizures Evaluation by Catechin Hydrate}

PTZ was injected initially on fore- and hind-limb myoclonic jerks (60 to $70 \mathrm{~s}$ ), which results in generalized clonic seizures produced on one side of the back. The selected doses of $10.0 \mathrm{mg} \mathrm{kg}^{-1} \mathrm{~b}$. wt. of CS coated-CH-PLGA NPs and CH-PLGA NPs were found to offer more significant protection $(p<0.001$ 
and $p<0.01$ ) with the decrement of the onset of myoclonic jerks, followed by clonic generalized seizures when compared with $\mathrm{CH}-\mathrm{S}$ (Figure 13). In our study, the CS-coated-CH-PLGA-NPs applied and illustrated better future treatment of antiepileptic activity at smaller doses of catechin hydrate, that is, $10.0 \mathrm{mg} \mathrm{kg}^{-1} \mathrm{~b}$. wt. in comparison with CH-S for ICES [21]. Furthermore, CS-coated-CH-PLGA-NPs showed a higher protective effect against PTZ-induced seizures, as compared with CH-PLGA NPs and $\mathrm{CH}-\mathrm{S}$. This is a great finding reported previously by Bonnet et al. and then by Vyas et al. [8,59], in which they showed a great suppression of bioelectric and epileptic activities, that is, induction by bicuculline, caffeine, or zero-Mg.
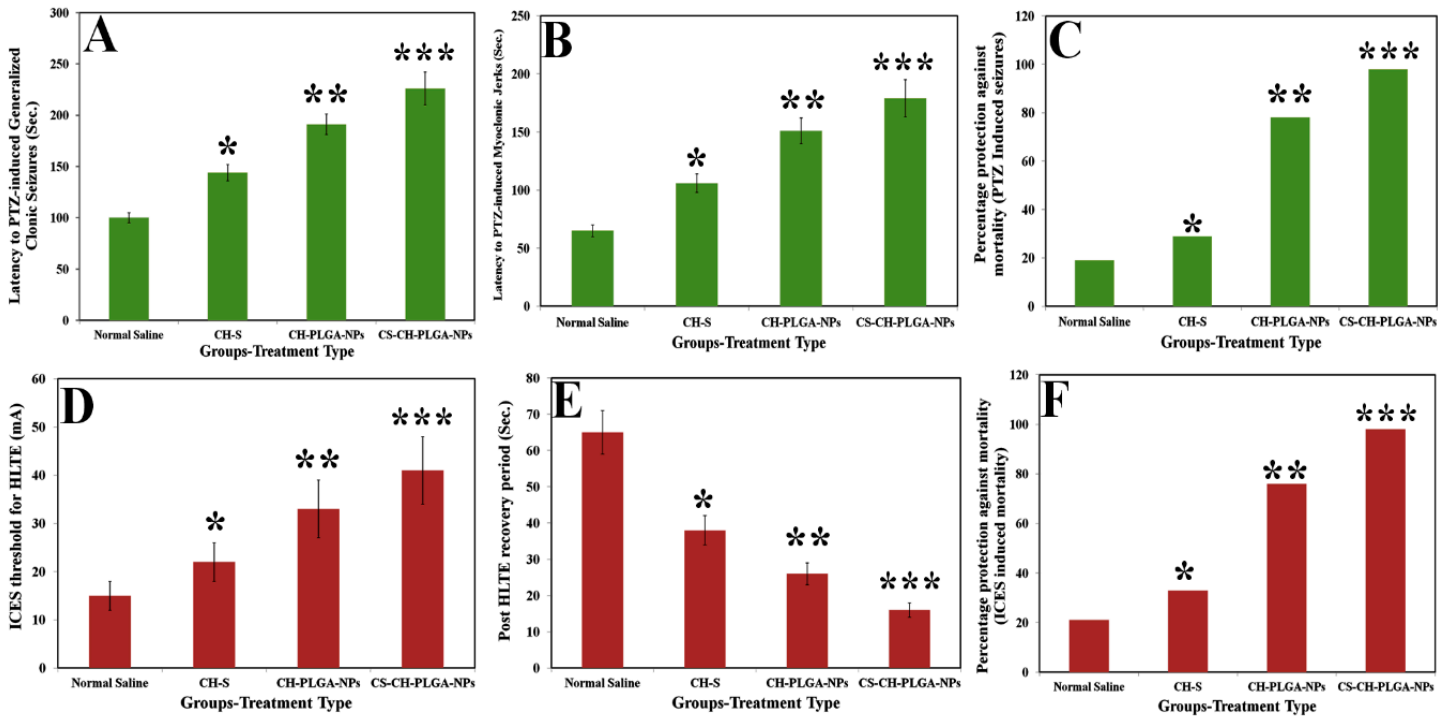

Figure 13. Effect of different nanoformulations of catechin hydrate on pentylenetetrazole (PTZ)-induced latency to generalized seizures (A), myoclonic jerks (B), \% against mortality owing to PTZ-induced seizures (C), increasing current electroshock (ICES)-induced threshold for HLTE (D), ICES-induced post-HLTE recovery time (E), and \% protective effect of different nanoformulations of catechin hydrate against ICES-induced mortality in rats $(\mathbf{F}){ }^{* * *}(p<0.001),{ }^{* *}(p<0.01)$, and ${ }^{*}(p<0.05)$.

The aforementioned observations can be concluded as follows: catechin hydrate as a CS-coated-CH-PLGA-NPs, when applied via the i.n. route, reaches the brain with maximum effectiveness, as compared with CH-PLGA-NPs and free $\mathrm{CH}$ when administered intranasally. There are many studies in the literature in favor of the i.n. route as the most effective route, in which they have mentioned that Lamotrigine, Clonazepam, Diazepam, and Midazolam loaded with mucoadhesive nanoformulation increased their effective treatment of the mentioned drugs for anticonvulsant activity [59-61].

\section{Conclusions}

CH-loaded-PLGA-NPs were formulated by the double emulsion-solvent evaporation method and optimized using a four-factor, three-level central composite design. The optimized PLGA-NPs were optimized on the basis of particle size, PDI, and ZP with the help of CCD. The optimized PLGA-NPs showed a smaller particle size, smaller PDI, and optimum Zeta potential, with higher entrapment efficiency, $\mathrm{CH}$ loading, and a high process yield following CS-coating. The CS-CH-PLGA-NPs showed a sustained release profile over $24.0 \mathrm{~h}$ with higher nasal permeation and prolonged retention for nose-to-brain delivery, and avoided hepatic first pass metabolism. The positive Zeta potential indicated the stability of CS-CH-PLGA-NPs owing to the presence of CS. A smooth surface of NPs was more authenticated via SEM and TEM, followed by DSC and FTIR studies exhibiting an entrapment of $\mathrm{CH}$ inside the optimized NPs. CS-CH-PLGA-NPs effectively crossed the BBB and also treated the epilepsy at smaller doses via the i.n. route as compared with $\mathrm{CH}-\mathrm{PLGA}-\mathrm{NPs}$ and pure $\mathrm{CH}-\mathrm{S}$. 
The developed UPLC-ESI-triple-quadrupole-MS/MS method was validated and used successfully for PK and biodistribution studies of optimized CS-CH-PLGA-NPs. Finally, the application of CS-CH-PLGA-NPs in the PTZ and ICES epilepsy model showed CS-CH-PLGA-NPs to be a novel, effective, and safe brain-targeted delivery system for the treatment of epilepsy.

Author Contributions: Conceptualization, N.A.; methodology, N.A., R.A., R.A.A., H.M.A.A., A.S.A.-R.; software, N.A., M.A., M.S.; validation, N.A., R.A., R.A.A., H.M.A.A., A.S.A.-R.; formal analysis, N.A., R.A., R.A.A., H.M.A.A., A.S.A.-R.; investigation, N.A., R.A., R.A.A., H.M.A.A., A.S.A.-R., M.A., M.S.; resources, N.A.; data curation, N.A.; writing - original draft preparation, N.A., R.A., R.A.A., H.M.A.A., A.S.A.-R.; writing-review and editing, N.A., R.A., R.A.A., H.M.A.A., A.S.A.-R.; visualization, N.A., R.A., R.A.A., H.M.A.A., A.S.A.-R., M.A., M.S.; supervision, N.A.; project administration, N.A.; funding acquisition, N.A. All authors have read and agreed to the published version of the manuscript.

Funding: This research received no external funding.

Acknowledgments: We are also very thankful to Animal House, Institute for Research and Medical Consultations (IRMC), Imam Abdulrahman Bin Faisal University, Dammam, Kingdom of Saudi Arabia.

Conflicts of Interest: The authors declare no conflict of interest.

\section{List of Abbreviations}

Catechin hydrate: CH; CS: chitosan; nanoparticles: NPs; CS-CH-PLGA-NPs: chitosan-coated catechin hydrate-loaded PLGA nanoparticles; polyvinyl alcohol: PVA; dichloromethane: DCM; ultra high performance liquid chromatography mass spectroscopy and mass spectroscopy: UHPLC-MS/MS; electrospray ionization: ESI; pharmacokinetic: PK; bioavailability: BA; polydispersity index: PDI; scanning electron microscope: SEM; transmission electron microscope: TEM; biopharmaceutical classification system: BCS; loading capacity: LC; entrapment efficiency: EE; differential scanning calorimetry: DSC; Fourier transform infrared spectroscopy: FTIR; attenuated total reflection: ATR; phosphate buffered solution: PBS; method development and method validation: MDMV; calibration curve: CC; internal standard: IS; catechin hydrate suspension: $\mathrm{CH}-\mathrm{S}$; liquid-liquid extraction: LLE: lower limit of quantification: LLOQ; lower limit of quantification for quality control: LLOQQC; low quality control: LQC: middle quality control: MQC; high quality control: $\mathrm{HQC}$; maximum plasma concentration: $\mathrm{C}_{\max }$; elimination rate constant: $\mathrm{K}_{\mathrm{el}}$; time to Cmax: Tmax; half-life: $\mathrm{t}_{\frac{1}{2}}$; area under curve: AUC; lower limit of detection: LOD; lower limit of quantitation: LOQ; analysis of variance: ANOVA; pharmacokinetics: PKs; pharmacodynamics: PDs; positive: +ve; negative: -ve; optimized: opt; central nervous system/brain: CNS; blood brain barrier: BBB; increasing current electroshock: ICES; pentylenetetrazole: PTZ; central composite design: CCD.

\section{References}

1. Lathers, C.M.; Schraeder, P.L. Clinical pharmacology: Drugs as a benefit and/or risk in sudden unexpected death in epilepsy? J. Clin. Pharmacol. 2002, 42, 123-136. [CrossRef] [PubMed]

2. Lathers, C.M.; Schraeder, P.L. Stress and sudden death. Epilepsy Behav. 2006, 9, 236-242. [CrossRef] [PubMed]

3. Blum, D.E. New drugs for persons with epilepsy. Adv. Neurol. 1998, 76, 57-81. [PubMed]

4. Gupta, Y.K.; Malhotra, J. Antiepileptic drug therapy in the twenty first century. Indian J. Physiol. Pharmacol. 2000, 44, 8-23.

5. Rogawski, M.A. Mechanism-specific pathways for new antiepileptic drug discovery. Adv. Neurol. 1998, 76, 11-27.

6. Sarro, G.D.; Spagnolo, C.; Gareri, P.; Gallelli, L.; De Sarro, A. Gabapentin potentiates the antiseizure activity of certain anticonvulsants in DBA/2 mice. Eur. J. Pharmacol. 1998, 349, 179-185. [CrossRef]

7. Whittingham, T.S.; Warman, E.; Assaf, H.; Sick, T.J.; LaManna, J.C. Manipulating the intracellular environment of hippocampal slices: $\mathrm{pH}$ and high-energy phosphates. J. Neurosci. Methods 1989, 28, 83-91. [CrossRef]

8. Bonnet, U.; Bingmann, D.; Wiemann, M. Intracellular pH modulates spontaneous and epileptiform bioelectric activity of hippocampal CA3-neurones. Eur. Neuropsychopharmacol. 2000, 10, 97-103. [CrossRef]

9. Goyal, S.N.; Prajapati, C.P.; Gore, P.R.; Patil, C.R.; Mahajan, U.B.; Sharma, C.; Talla, S.P.; Ojha, S.K. Therapeutic Potential and Pharmaceutical Development of Thymoquinone: A Multitargeted Molecule of Natural Origin. Front. Pharmacol. 2017, 8, 656. [CrossRef]

10. Balentine, D.A.; Wiseman, S.A.; Bouwens, L.C. The chemistry of tea flavonoids. Crit. Rev. Food Sci. Nutr. 1997, 37, 693-704. [CrossRef]

11. Giovannucci, E. Meta-analysis of coffee consumption and risk of colorectal cancer. Am. J. Epidemiol. 1998, 147, 1043-1052. [CrossRef] [PubMed] 
12. Arts, I.C.; Hollman, P.C. Polyphenols and disease risk in epidemiologic studies. Am. J. Clin. Nutr. 2005, 81 (Suppl. 1), 317S-325S. [CrossRef] [PubMed]

13. Andersen, L.F.; Jacobs, D.R., Jr.; Carlsen, M.H.; Blomhoff, R. Consumption of coffee is associated with reduced risk of death attributed to inflammatory and cardiovascular diseases in the Iowa Women's Health Study. Am. J. Clin. Nutr. 2006, 83, 1039-1046. [CrossRef] [PubMed]

14. Arts, I.C.; Hollman, P.C.; Feskens, E.J.; Bueno de Mesquita, H.B.; Kromhout, D. Catechin intake might explain the inverse relation between tea consumption and ischemic heart disease: The Zutphen Elderly Study. Am. J. Clin. Nutr. 2001, 74, 227-232. [CrossRef]

15. Kuriyama, S.; Shimazu, T.; Ohmori, K.; Kikuchi, N.; Nakaya, N.; Nishino, Y.; Tsubono, Y.; Tsuji, I. Green tea consumption and mortality due to cardiovascular disease, cancer, and all causes in Japan: The Ohsaki study. JAMA 2006, 296, 1255-1265. [CrossRef] [PubMed]

16. Higdon, J.V.; Frei, B. Tea catechins and polyphenols: Health effects, metabolism, and antioxidant functions. Crit. Rev. Food Sci. Nutr. 2003, 43, 89-143. [CrossRef] [PubMed]

17. Xie, T.; Wang, W.P.; Mao, Z.F.; Qu, Z.Z.; Luan, S.Q.; Jia, L.J.; Kan, M.C. Effects of epigallocatechin-3-gallate on pentylenetetrazole-induced kindling, cognitive impairment and oxidative stress in rats. Neurosci. Lett. 2012, 516, 237-241. [CrossRef]

18. Martinc, B.; Grabnar, I.; Vovk, T. Antioxidants as a preventive treatment for epileptic process: A review of the current status. Curr. Neuropharmacol. 2014, 12, 527-550. [CrossRef]

19. Yilmaz, Y.; Toledo, R.T. Major flavonoids in grape seeds and skins: Antioxidant capacity of catechin, epicatechin, and gallic acid. J. Agric. Food Chem. 2004, 52, 255-260. [CrossRef]

20. Li, Q.; Zhao, H.F.; Zhang, Z.F.; Liu, Z.G.; Pei, X.R.; Wang, J.B.; Li, Y. Long-term green tea catechin administration prevents spatial learning and memory impairment in senescence-accelerated mouse prone- 8 mice by decreasing $A \beta_{1-42}$ oligomers and upregulating synaptic plasticity-related proteins in the hippocampus. Neuroscience 2009, 163, 741-749. [CrossRef]

21. Ahmad, N.; Ahmad, R.; Alam, M.A.; Ahmad, F.J.; Amir, M. Impact of ultrasonication techniques on the preparation of novel Amiloride-nanoemulsion used for intranasal delivery in the treatment of epilepsy. Artif. Cells Nanomed. Biotechnol. 2018, 23, 1-16. [CrossRef] [PubMed]

22. Ahmad, N.; Ahmad, R.; Abbas Naqvi, A.; Ashafaq, M.; Alam, M.A.; Ahmad, F.J.; Al-Ghamdi, M.S. The effect of safranal loaded mucoadhesive nanoemulsion on oxidative stress markers in cerebral ischemia. Artif. Cells Nanomed. Biotechnol. 2017, 45, 775-787. [CrossRef] [PubMed]

23. Ahmad, N.; Ahmad, R.; Naqvi, A.A.; Alam, M.A.; Ashafaq, M.; Abdur Rub, R.; Ahmad, F.J. Intranasal delivery of quercetin-loaded mucoadhesive nanoemulsion for treatment of cerebral ischaemia. Artif. Cells Nanomed. Biotechnol. 2018, 46, 717-729. [CrossRef] [PubMed]

24. Torchilin, V.P. Micellar nanocarriers: Pharmaceutical perspectives. Pharm. Res. 2007, 24, 1-16. [CrossRef] [PubMed]

25. Ahmad, N.; Ahmad, R.; Alam, M.A.; Samim, M.; Iqbal, Z.; Ahmad, F.J. Quantification and evaluation of thymoquinone loaded mucoadhesive nanoemulsion for treatment of cerebral ischemia. Int. J. Biol. Macromol. 2016, 88, 320-332. [CrossRef] [PubMed]

26. Fernandez-Urrusuno, R.; Romani, D.; Calvo, D. Development of a Freeze Dried Formulation of Insulin-Loaded Chitosan Nanoparticles Intended for Nasal Administration. STP Pharm Sci. 1999, 9, 429-436.

27. Md, S.; Khan, R.A.; Mustafa, G.; Chuttani, K.; Baboota, S.; Sahni, J.K.; Ali, J. Bromocriptine loaded chitosan nanoparticles intended for direct nose to brain delivery: Pharmacodynamic, pharmacokinetic and scintigraphy study in mice model. Eur. J. Pharm. Sci. 2013, 48, 393-405. [CrossRef]

28. Ahmad, N. Rasagiline-encapsulated chitosan-coated PLGA nanoparticles targeted to the brain in the treatment of parkinson's disease. J. Liq. Chromatogr. Relat. Technol. 2017, 40, 677-690. [CrossRef]

29. Bonaccorso, A.; Musumeci, T.; Carbone, C.; Vicari, L.; Lauro, M.R.; Puglisi, G. Revisiting the role of sucrose in PLGA-PEG nanocarrier for potential intranasal delivery. Pharm. Dev. Technol. 2018, 23, 265-274. [CrossRef]

30. Seju, U.; Kumar, A.; Sawant, K.K. Development and evaluation of olanzapine-loaded PLGA nanoparticles for nose-to-brain delivery: In vitro and in vivo studies. Acta Biomater. 2011, 7, 4169-4176. [CrossRef]

31. Ahmad, N.; Ahmad, R.; Al Qatifi, S.; Alessa, M.; Al Hajji, H.; Sarafroz, M. A bioanalytical UHPLC based method used for the quantification of Thymoquinone-loaded-PLGA-nanoparticles in the treatment of epilepsy. BMC Chem. 2020, 14, 10. [CrossRef] [PubMed] 
32. Zhou, L.; He, H.; Li, M.C.; Song, K.; Cheng, H.N.; Wu, Q. Morphological influence of cellulose nanoparticles (CNs) from cottonseed hulls on rheological properties of polyvinyl alcohol/CN suspensions. Carbohydr. Polymers 2016, 153, 445-454. [CrossRef] [PubMed]

33. Chang, S.F.; Huang, K.C.; Cheng, C.C.; Su, Y.P.; Lee, K.C.; Chen, C.N.; Chang, H.I. Glucose adsorption to chitosan membranes increases proliferation of human chondrocyte via mammalian target of rapamycin complex 1 and sterol regulatory element-binding protein-1 signaling. J. Cell. Physiol. 2017, 232, 2741-2749. [CrossRef] [PubMed]

34. Ahmad, N.; Ahmad, R.; Naqvi, A.A.; Alam, M.A.; Ashafaq, M.; Samim, M.; Iqbal, Z.; Ahmad, F.J. Rutin-Encapsulated Chitosan Nanoparticles Targeted to the Brain in the Treatment of Cerebral Ischemia. Int. J. Biol. Macromol. 2016, 91, 640-655. [CrossRef] [PubMed]

35. Badran, M.M.; Mady, M.M.; Ghannam, M.M.; Shakeel, F. Preparation and Characterization of Polymeric Nanoparticles Surface Modified with Chitosan for Target Treatment of Colorectal Cancer. Int. J. Biol. Macromol. 2017, 95, 643-649. [CrossRef]

36. Sapozhnikova, Y. Development of liquid chromatography-tandem mass spectrometry method for analysis of polyphenolic compounds in liquid samples of grape juice, green tea and coffee. Food Chem. 2014, 150, 87-93. [CrossRef]

37. Svoboda, P.; Vlčková, H.; Nováková, L. Development and validation of UHPLC-MS/MS method for determination of eight naturally occurring catechin derivatives in various tea samples and the role of matrix effects. J. Pharm. Biomed. Anal. 2015, 114, 62-70. [CrossRef]

38. Taamalli, A.; Arráez-Román, D.; Abaza, L.; Iswaldi, I.; Fernández-Gutiérrez, A.; Zarrouk, M.; Segura-Carretero, A. LC-MS-based metabolite profiling of methanolic extracts from the medicinal and aromatic species Mentha pulegium and Origanum majorana. Phytochem. Anal. 2015, 26, 320-330. [CrossRef] [PubMed]

39. Dias, A.L.; Rozet, E.; Larondelle, Y.; Hubert, P.; Rogez, H.; Quetin-Leclercq, J. Development and validation of an UHPLC-LTQ-Orbitrap MS method for non-anthocyanin flavonoids quantification in Euterpe oleracea juice. Anal. Bioanal. Chem. 2013, 405, 9235-9249. [CrossRef]

40. Poon, G.K. Analysis of catechins in tea extracts by liquid chromatography-electrospray ionization mass spectrometry. J. Chromatogr. A 1998, 794, 63-74. [CrossRef]

41. Chang, C.L.; Wub, R.T. Quantification of (+)-catechin and (-)-epicatechin in coconut water by LC-MS. Food Chem. 2011, 126, 710-717. [CrossRef]

42. Nelson, B.C.; Sharpless, K.E. Quantification of the predominant monomeric catechins in baking chocolate standard reference material by LC/APCI-MS. J. Agric. Food Chem. 2003, 51, 531-537. [CrossRef] [PubMed]

43. Jaitz, L.; Siegl, K.; Eder, R.; Rak, G.; Abranko, L.; Koellensperger, G.; Hann, S. LC-MS/MS analysis of phenols for classification of red wine according to geographic origin, grape variety and vintage. Food Chem. 2010, 122, 366-372. [CrossRef]

44. Lendoiro, E.; de Castro, A.; Fernández-Vega, H.; Cela-Pérez, M.C.; López-Vilariño, J.M.; González-Rodríguez, M.V.; Cruz, A.; López-Rivadulla, M. Molecularly imprinted polymer for selective determination of $\Delta^{9}$-tetrahydrocannabinol and 11-nor- $\Delta^{9}$-tetrahydrocannabinol carboxylic acid using LC-MS/MS in urine and oral fluid. Anal. Bioanal. Chem. 2014, 406, 3589-3597. [CrossRef] [PubMed]

45. Ahmad, N.; Alam, M.A.; Ahmad, R.; Umar, S.; Jalees Ahmad, F. Improvement of oral efficacy of Irinotecan through biodegradable polymeric nanoparticles through in vitro and in vivo investigations. J. Microencapsul. 2018, 35, 327-343. [CrossRef] [PubMed]

46. Ahmad, N.; Al-Subaiec, A.M.; Ahmad, R.; Sharma, S.; Alam, M.A.; Ashafaq, M.; Abdur Rub, R.; Ahmad, F.J. Brain-targeted glycyrrhizic-acid-loaded surface decorated nanoparticles for treatment of cerebral ischaemia and its toxicity assessment. Artif. Cells Nanomed. Biotechnol. 2019, 47, 475-490. [CrossRef] [PubMed]

47. Ali, A.; Ahmad, F.J.; Pillai, K.K.; Vohora, D. Evidence of the antiepileptic potential of amiloride with neuropharmacological benefits in rodent models of epilepsy and behavior. Epilepsy Behav. 2004, 5, 322-328. [CrossRef]

48. Kitano, Y.; Usui, C.; Takasuna, K.; Hirohashi, M.; Nomura, M. Increasing-current electroshock seizure test: A new method for assessment of anti- and pro-convulsant activities of drugs in mice. J. Pharmacol. Toxicol. Methods 1996, 35, 25-29. [CrossRef] 
49. Mundargi, R.C.; Srirangarajan, S.; Agnihotri, S.A.; Patil, S.A.; Ravindra, S.; Setty, S.B.; Aminabhavi, T.M. Development and Evaluation of Novel Biodegradable Microspheres Based on Poly(D, L-Lactide-co-Glycolide) and Poly(Epsilon-Caprolactone) for Controlled Delivery of Doxycycline in the Treatment of Human Periodontal Pocket: In Vitro and In Vivo Studies. J. Control. Release 2007, 119, 59-68. [CrossRef]

50. Mainardes, R.M.; Evangelista, R.C. PLGA Nanoparticles Containing Praziquantel: Effect of Formulation Variables on Size Distribution. Int. J. Pharm. 2005, 290, 137-144. [CrossRef]

51. Mittal, G.; Sahana, D.K.; Bhardwaj, V.; Kumar, M.N. Estradiol Loaded PLGA Nanoparticles for Oral Administration: Effect of Polymer Molecular Weight and Copolymer Composition on Release Behavior in vitro and in vivo. J. Control. Release 2007, 119, 77-85. [CrossRef]

52. Wang, Y.; Li, P.; Kong, L. Chitosan-Modified PLGA Nanoparticles with Versatile Surface for Improved Drug Delivery. AAPS PharmSciTech 2013, 14, 585-592. [CrossRef] [PubMed]

53. Sanna, V.; Roggio, A.M.; Posadino, A.M. Novel Docetaxel-Loaded Nanoparticles Based on Poly(Lactide-co-Caprolactone) and Poly (Lactide-co-Glycolide-Cocaprolactone) for Prostate Cancer Treatment: Formulation, Characterization, and Cytotoxicity Studies. Nanoscale Res. Lett. 2011, 6, 260-270. [CrossRef] [PubMed]

54. Ahmad, N.; Ahmad, R.; Alam, M.A.; Ahmad, F.J.; Amir, M.; Pottoo, F.H.; Sarafroz, M.; Jafar, M.; Umar, K. Daunorubicin oral bioavailability enhancement by surface coated natural biodegradable macromolecule chitosan based polymeric nanoparticles. Int. J. Biol. Macromol. 2019, 128, 825-838. [CrossRef] [PubMed]

55. Richter, T.; Keipert, S. In vitro Permeation Studies Comparing Bovine Nasal Mucosa, Porcine Cornea and Artificial Membrane: Androstenedione in Microemulsions and Their Components. Eur. J. Pharm. Biopharm. 2004, 58, 137-143. [CrossRef] [PubMed]

56. US FDA. Guidance for Industry Bioanalytical Method Validation. 2001. Available online: http://www.fda. gov/downloads/Drugs/GuidanceComplianceRegulatoryInformation/Guidances/UCM070107.pdf (accessed on 24 May 2018).

57. Faiyazuddin, M.; Ahmad, N.; Khar, R.K.; Bhatnagar, A.; Ahmad, F.J. Stabilized terbutaline submicron drug aerosol for deep lungs deposition: Drug assay, pulmonokinetics and biodistribution by UHPLC/ESI-q-TOF-MS method. Int. J. Pharm. 2012, 434, 59-69. [CrossRef]

58. Ge, H.; Hu, Y.; Jiang, X.; Cheng, D.; Yuan, Y.; Bi, H.; Yang, C. Preparation, characterization, and drug release behaviors of drug nimodipine-loaded poly(epsilon-caprolactone)-poly(ethylene oxide)-poly(epsilon-caprolactone) amphiphilic triblock copolymer micelles. J. Pharm. Sci. 2002, 91, 1463-1473. [CrossRef]

59. Vyas, T.K.; Babbar, A.K.; Sharma, R.K.; Singh, S.; Misra, A. Intranasal mucoadhesive microemulsions of clonazepam: Preliminary studies on brain targeting. J. Pharm. Sci. 2006, 95, 570-580. [CrossRef]

60. Shende, A.J.; Patil, R.R.; Devarajan, P.V. Microemulsion of Lamotrigine for nasal delivery. Ind. J. Pharm. Sci. 2007, 69, 721-722.

61. Botner, S.; Sintov, A.C. Intranasal delivery of two benzodiazepines, Midazolam and Diazepam, by a microemulsion system. J. Pharmacol. Pharm. 2011, 2, 180-188. [CrossRef]

(C) 2020 by the authors. Licensee MDPI, Basel, Switzerland. This article is an open access article distributed under the terms and conditions of the Creative Commons Attribution (CC BY) license (http://creativecommons.org/licenses/by/4.0/). 